\title{
FLIM as a Promising Tool for Cancer Diagnosis and Treatment Monitoring
}

Cite as

Nano-Micro Lett.

(2021) 13:133

Received: 21 March 2021

Yuzhen Ouyang ${ }^{1,2,3}$, Yanping Liu ${ }^{2,4,5} \bowtie$, Zhiming M. Wang ${ }^{6}$, Zongwen Liu ${ }^{7}$,

Accepted: 19 April 2021

Published online: 3 June 2021

(C) The Author(s) 2021 Minghua $\mathrm{Wu}^{1,2} \bowtie$

\section{HIGHLIGHTS}

- Fluorescence lifetime imaging microscopy (FLIM) applications for cancer diagnosis and treatment monitoring combined with reduced form of nicotinamide adenine dinucleotide, Förster resonance energy transfer (FRET), and biosensors are reviewed.

- Principles of FLIM, previous clinical applications, and development history are introduced.

- The current challenges and prospects for the potential of FLIM for cancer diagnosis and promotion of the effect of anti-cancer treatment are discussed.

ABSTRACT Fluorescence lifetime imaging microscopy (FLIM) has been rapidly developed over the past 30 years and widely applied in biomedical engineering. Recent progress in fluorophore-dyed probe design has widened the application prospects of fluorescence. Because fluorescence lifetime is sensitive to microenvironments and molecule alterations, FLIM is promising for the detection of pathological conditions. Current cancer-related FLIM applications can be divided into three main categories: (i) FLIM with autofluorescence molecules in or out of a cell, especially with reduced form of nicotinamide adenine dinucleotide, and flavin adenine dinucleotide for cellular metabolism research; (ii) FLIM with Förster resonance energy transfer for monitoring protein interactions; and (iii) FLIM with fluorophore-dyed probes for specific aberration detection. Advancements in nanomaterial production and efficient calculation systems, as well as novel cancer biomarker discoveries, have promoted FLIM optimization, offering more opportunities for medical research

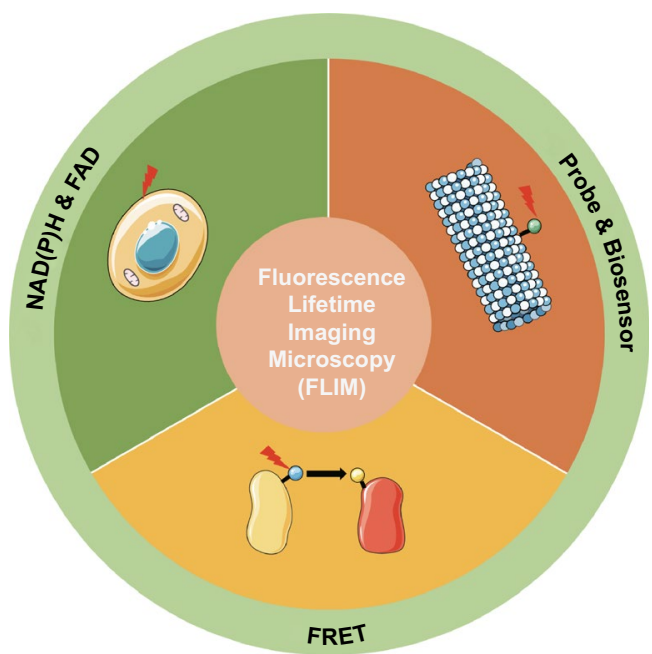

Yuzhen Ouyang and Yanping Liu contributed equally to this work.

$\triangle$ Yanping Liu, liuyanping@csu.edu.cn; Zongwen Liu, zongwen.liu@sydney.edu.au; Minghua Wu, wuminghua554@aliyun.com

1 Hunan Provincial Tumor Hospital and the Affiliated Tumor Hospital of Xiangya Medical School, Central South University, Changsha 410013, Hunan, People's Republic of China

2 School of Physics and Electronics, Hunan Key Laboratory for Super-Microstructure and Ultrafast Process, Central South University, 932 South Lushan Road, Changsha 410083, Hunan, People's Republic of China

3 The Key Laboratory of Carcinogenesis of the Chinese Ministry of Health, The Key Laboratory of Carcinogenesis and Cancer Invasion of the Chinese Ministry of Education, Cancer Research Institute, Central South University, Changsha 410008, Hunan, People's Republic of China

4 Shenzhen Research Institute of Central South University, A510a, Virtual University Building, Nanshan District, Southern District, High-tech Industrial Park, Yuehai Street, Shenzhen, People's Republic of China

5 State Key Laboratory of High-Performance Complex Manufacturing, Central South University, 932 South Lushan Road, Changsha 410083, Hunan, People's Republic of China

${ }^{6}$ Institute of Fundamental and Frontier Sciences, University of Electronic Science and Technology of China, Chengdu 610054, Sichuan, People's Republic of China

7 School of Chemical and Biomolecular Engineering, The University of Sydney, Sydney, NSW 2006, Australia 
and applications to cancer diagnosis and treatment monitoring. This review summarizes cutting-edge researches from 2015 to 2020 on cancer-related FLIM applications and the potential of FLIM for future cancer diagnosis methods and anti-cancer therapy development. We also highlight current challenges and provide perspectives for further investigation.

KEYWORDS Fluorescence lifetime imaging microscopy; Förster resonance energy transfer; Reduced form of nicotinamide adenine dinucleotide; Biosensors; Cancer

\section{Introduction}

Fluorescence has become an essential tool for scientific research especially following the discovery of fluorescent proteins in the last century because of its biocompatibility [1]. Multiple characteristic parameters of fluorescence can be applied for constructing images, including intensity, spectrum, and lifetime. Considering the advantages of fluorescence lifetime, such as high sensitivity to molecular conformation and environment changes, as well as the ability distinguishing molecules with overlapping spectra, fluorescence lifetime, an intrinsic property of fluorescent molecule, is promising for biomedical applications [2, 3].

To accurately detect fluorescence lifetime, fluorescence lifetime imaging microscopy (FLIM) has been continuously improved over the decades, which can be summarized as the imaging speed, the accuracy of fluorescence lifetime measurements, and the imaging resolution improvement [3]. Through the innovative union of the ultrashort laser with laser scanning, the first time-correlated single photon counting (TCSPC)-FLIM was born in the 1980s. However, because of the large photon requirement of TCSPC-FLIM for accurate lifetime measurements, imaging speed is one of its shortcomings. The wide-field imaging, single-photon avalanche diode (SPAD) arrays, improved scanning methods, and better fitting algorithms all can accelerate imaging and numerous fast FLIM techniques have been reviewed in detail $[4,5]$. Besides, after the TCSPC-FLIM invention, some other problems, including depth penetration restriction, background fluorescence interference, photo-bleaching, also impeded wider clinical applications of FLIM such as fluorescence lifetime detection in thick samples. Therefore, FLIM resolution and lifetime measurement accuracy improvement are the issues attracting a great number of researchers' attention. For this purpose, the two-photon FLIM (TP-FLIM) technique is a promising method. It is implemented by using two longwave photons to excite a fluorescence molecule, leading to the emission of shortwave photons at high intensity. From 1990 to 2010, the first two-photon microscope, the first two-photon application on human skin, and the first clinical two-photon time-resolved imaging were reported in succession. Moreover, based on material innovations, the applications of TP-FLIM imaging can be further extended by thermally activated delayedfluorescence fluorophores with prolonged fluorescence lifetimes and high two-photon absorption efficiencies [6, 7]. Recently, various applications of TP-FLIM, including digestive tract tumor diagnosis, have also been reviewed, proving the clinical application potential of TP-FLIM $[8,9]$. Furthermore, the multiphoton FLIM method has also been developed since the first successful application of clinical multiphoton tomography (MPT) in 2002. Later, clinical multiphoton fluorescence endoscopy was also successfully constructed [10]. Through its continuous development, nowadays, numerous multiphoton FLIM tomographs such as MPTcompact and DermaInspect are already in clinical use in many countries [11].

Based on the continuous development of these instruments and analysis methods, the range of FLIM applications has been broadened in biomedical research. Over the past few decades, this technique has been used for the detection of inter-protein interactions, calcium concentrations, and other applications [12, 13]. As for clinical medicine, FLIM has been applied to inflammation site detection, dermatosis differential diagnosis, tumor boundary delineation, etc. Notably, among these research fields, cancer diagnosis and treatment has attracted significant attention based on the high incidence and mortality of cancer, which necessitate early cancer diagnosis and anti-cancer drug efficiency enhancement. FLIM is a promising technique for such applications. Therefore, rather than to comprehensively summarize the FLIM techniques development or its extensive applications in numerous research fields, including cosmetic products and neuroscience which are already available elsewhere, this review mainly introduces the FLIM applications related to cancer diagnosis and anti-cancer treatment improvement in three main research areas: (i) FLIM with autofluorescence 
coenzymes for monitoring cell metabolism, (ii) FLIM in combination with Förster resonance energy transfer (FRET) pairs for detecting molecule interactions, and (iii) FLIM with well-designed probes for detecting intracellular or extracellular environments. In Fig. 1, it is evident that the number of publications on FLIM is increasing annually, which highlights the enormous potential of FLIM in various fields.

\section{Principles of FLIM}

As shown in Fig. 2a, the basic principle of fluorescence is that when a fluorophore is excited to a higher energy state by absorbing one or more photons, it returns to its ground state through a radiative or non-radiative process. Fluorescence emission is a radiative process, which can be recorded by an apparatus, and the fluorescence decay curve can be fitted by the algorithm $[14,15]$. There are two rates determining the fluorescence lifetime $(\tau)$ : The radiative decay rate $\Gamma$ and the nonradiative decay rate $k . \Gamma$ is based on the fluorophore electronic properties, whereas, $k$ is relevant to the molecule interaction, FRET, etc. Under the simplest condition, fluorescence decay can be fitted as following exponential decay:

$\frac{\mathrm{d} N(t)}{\mathrm{d} t}=-(\Gamma+k) N(t)$

$N(t)=N_{0} e^{-(\Gamma+k) t}=N_{0} e^{-t / \tau}$

The $N(0)$ and $N(t)$ are the initial number of fluorescent molecules and the fluorophore population on the first singlet state, respectively. Therefore, the fluorescence lifetime is:

$\tau=\frac{1}{\Gamma+k}$

which indicates the average time fluorophores on the excited state before returning to the ground state. If a fluorescence decay curve is constructed as the chart in Fig. 2a, the fluorescence lifetime can be calculated as the time when the intensity decreases to $1 / \mathrm{e}$ of the initial intensity.

As for the FLIM apparatus, the basic setup for fluorescence imaging is presented in Fig. 2b. In FLIM, single-photon detectors and photon timing techniques are incorporated into this setup for lifetime measurement [16]. Single-photon detectors in FLIM are typically based on photon amplification through electrical current generation when photons impact a photovoltaic such as the photomultiplier tube
(PMT) or avalanche photodiode (APD). The photon timing apparatus then transforms the photon signal into a digital signal for further lifetime analysis, such as leading-edge and constant fraction discriminator (CFD) analysis, timeto-amplitude conversion (TAC), analog-to-digital conversion (ADC), time-to-digital conversion (TDC), and streak camera analysis.

As shown in Table 1, FLIM setups are diverse because FLIM depicts the fluorescence lifetime $\tau$ in both the time domain (TD) and frequency domain (FD) [17]. TD-FLIM includes streak cameras, the time gate technique, and TCSPC, whose principles have been introduced previously [18]. Among these TD methods, the most prevalent technique is TCSPC [19]. The basic principles of TCSPC can be briefly illustrated as the scheme in Fig. 2c. The laser will firstly be separated into two beams, one of which enters into the imaging system to excite sample to produce a fluorescence signal. The fluorescence signal will be recorded by the micro-channel-plate/photomultiplier (MCP/PMT) and be amplified by the amplifier to generate a start signal for TAC. While the other laser passes a fast photodiode to produce a stop signal for TAC system. After the TAC and ADC signal conversions, photons are classified into different time channels based on the arrival time. Through computer processing, a fluorescence decay curve is then generated, and the fluorescence lifetime of each pixel is used to perform FLIM imaging. Besides, the time-gated method is based on the detector, such as the charge-coupled device camera (CCD), to record fluorescence decay at different time gates for reconstructing the exponential fluorescence decay curve [20]. The streak camera method mainly consists of a streak camera, a pulse laser, and a picker. Through scanning electric field accelerations, photoelectrons arriving at different time will be separated in space. The fluorescence lifetime can be obtained by analyzing the resulting spatial distribution [21].

FD-FLIM is based on modulation technology for generating a sinusoid. As shown in Fig. 2d, the signal generator first generates a sine-wave pulse that will travel through a predefined light pathway to excite the sample. The emission pulse wave is recorded by instruments, and based on computer processing, an emission wave is generated, as shown in Fig. 2d. Analyzing the change in demodulation represented by the $M$ (counted by Eq. (4)) and the phase delay $\Delta \varphi$, the fluorescence lifetime (fluorescence module lifetime $\left(\tau_{M}\right)$ and phase shift lifetime $\left.\left(\tau \triangle_{\varphi}\right)\right)$ can be calculated directly using Eqs. (5) and (6). 
Table 1 Time domain \& Frequency domain FLIM

\begin{tabular}{|c|c|c|c|c|c|c|c|}
\hline \multicolumn{2}{|l|}{ Method } & \multirow{2}{*}{$\begin{array}{l}\text { Excitation laser } \\
\text { Pulsed laser }\end{array}$} & \multirow{2}{*}{$\begin{array}{l}\text { Detector } \\
\text { PMT } \\
\text { APD/SPAD } \\
\text { Hybrid detector }\end{array}$} & \multirow{2}{*}{$\begin{array}{l}\text { Imaging method } \\
\begin{array}{l}\text { Scanning imag- } \\
\text { ing }\end{array}\end{array}$} & \multirow[b]{2}{*}{$\begin{array}{l}\text { Advantages } \\
\text { High- resolution } \\
\text { Reduced back- } \\
\text { ground blur } \\
\text { Most widely } \\
\text { used } \\
\text { Accurate meas- } \\
\text { urement } \\
\text { Low photodam- } \\
\text { age and pho- } \\
\text { tobleaching }\end{array}$} & \multirow{2}{*}{$\begin{array}{l}\text { Shortcomings } \\
\text { Slow imaging } \\
\text { speed } \\
\text { High require- } \\
\text { ment of } \\
\text { hardware and } \\
\text { software }\end{array}$} & \multirow{2}{*}{$\begin{array}{l}\text { Refs. } \\
{[3,16-19]}\end{array}$} \\
\hline Time domain & TCSPC & & & & & & \\
\hline & Time gate & Pulsed laser & $\begin{array}{l}\text { CCD/ICCD } \\
\mathrm{PMT}\end{array}$ & $\begin{array}{l}\text { Wide-field imag- } \\
\text { ing }\end{array}$ & $\begin{array}{l}\text { Fast imaging } \\
\text { speed } \\
\text { Low photodam- } \\
\text { age } \\
\text { Convenient spa- } \\
\text { tial information } \\
\text { acquisition }\end{array}$ & $\begin{array}{l}\text { High-resolution } \\
\text { demand for } \\
\text { instruments } \\
\text { Poor accuracy of } \\
\text { lifetime meas- } \\
\text { urement } \\
\text { Unsuitable for } \\
\text { multicompo- } \\
\text { nent measure- } \\
\text { ment } \\
\text { Scarce optical } \\
\text { sectioning } \\
\text { capability }\end{array}$ & {$[3,17,18,20]$} \\
\hline & Streak camera & Pulsed laser & Streak camera & $\begin{array}{l}\text { Multidimen- } \\
\text { sional } \\
\text { Scanning imag- } \\
\text { ing }\end{array}$ & $\begin{array}{l}\text { High-resolution } \\
\text { Low photodam- } \\
\text { age } \\
\text { Fast imaging } \\
\text { speed }\end{array}$ & $\begin{array}{l}\text { High cost } \\
\text { High technical } \\
\text { demanding }\end{array}$ & {$[16,17,21]$} \\
\hline Frequency domain & & $\begin{array}{l}\text { Sinusoidally } \\
\text { modulated } \\
\text { light/Pulsed } \\
\text { laser (High } \\
\text { repetition rate)/ } \\
\text { Continous } \\
\text { wave (CW) }\end{array}$ & CCD & $\begin{array}{l}\text { Scanning/Wide- } \\
\text { field imaging }\end{array}$ & $\begin{array}{l}\text { Low requirement } \\
\text { of hardware } \\
\text { and software } \\
\text { Fast imaging } \\
\text { speed (wide } \\
\text { imaging) } \\
\text { Low photodam- } \\
\text { age and pho- } \\
\text { tobleaching }\end{array}$ & $\begin{array}{l}\text { High photodam- } \\
\text { age } \\
\text { Background } \\
\text { interference } \\
\text { (Wide-field } \\
\text { imaging) } \\
\text { Limited photon } \\
\text { timing resolu- } \\
\text { tion (Wide- } \\
\text { field) } \\
\text { Restricted } \\
\text { imaging speed } \\
\text { (scanning } \\
\text { imaging) and } \\
\text { imaging depth } \\
\text { (wide-field } \\
\text { imaging) }\end{array}$ & {$[3,16-18]$} \\
\hline
\end{tabular}

$P M T$ photomultiplier tube, $A P D$ avalanche photodiode, $C C D$ charge-coupled device, $I C C D$ : intensified charge-coupled device

$$
\begin{aligned}
\mathrm{M} & =\frac{a / b}{A / B} \\
\tau_{\mathrm{M}} & =\frac{1}{\omega} \sqrt{\frac{1}{M^{2}}-1}
\end{aligned}
$$

$$
\tau_{\Delta \varphi}=\frac{\tan (\Delta \varphi)}{\omega}
$$

To fit the fluorescence decay curves, in the fitting analysis method, two types of exponential decays are commonly used. Equation (7) is used for single-exponential analysis, 

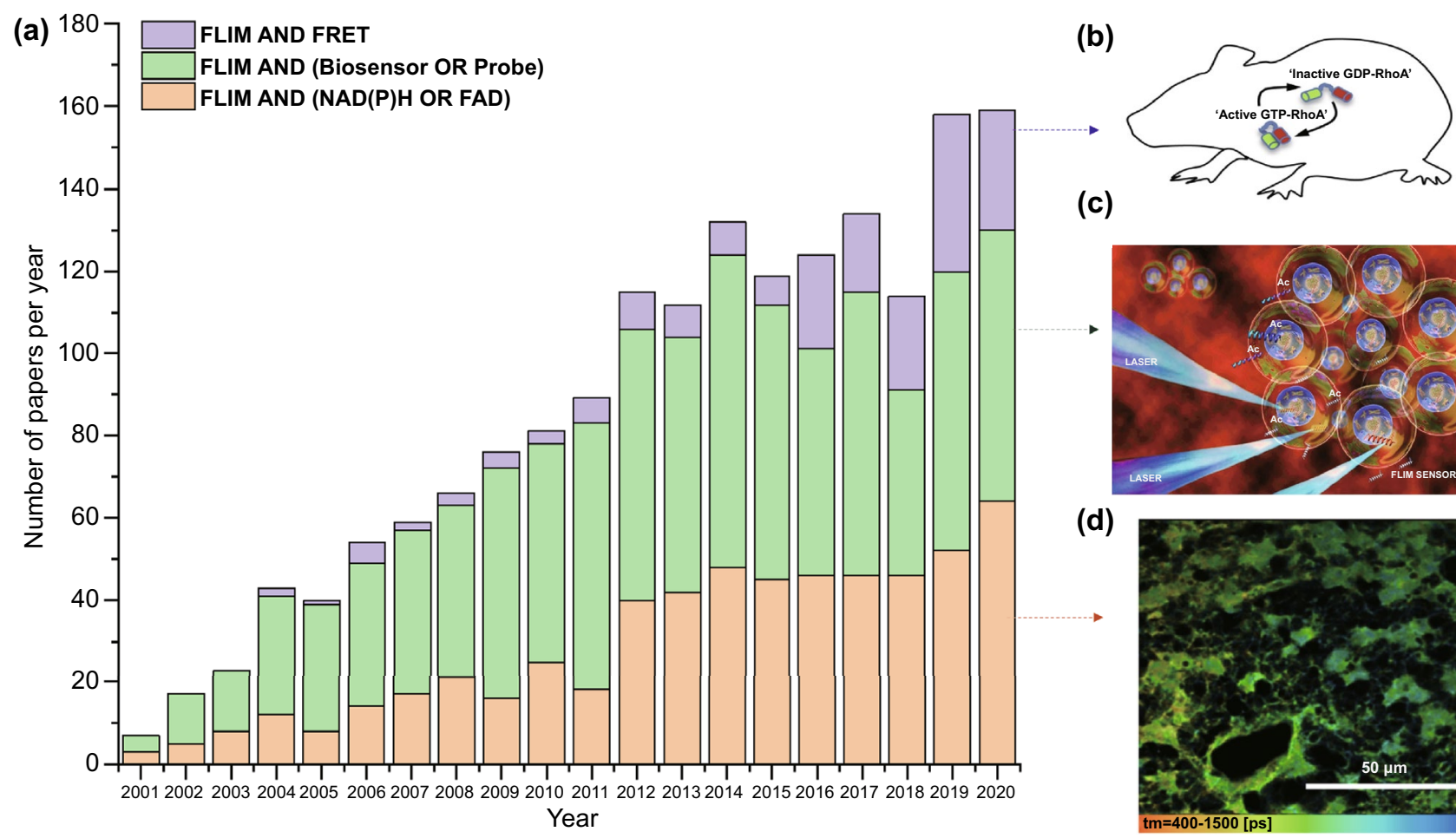

(c)

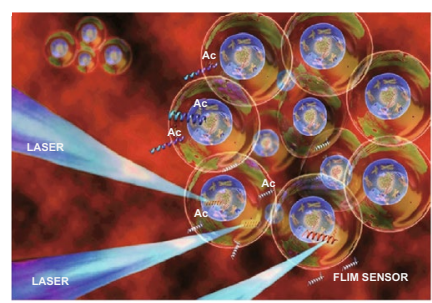

(d)

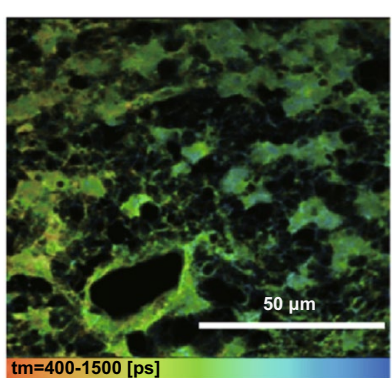

Fig. 1 Numbers of publications per year in the field of FLIM with NAD(P)H or FAD (orange), probes or biosensors (green), and FRET (purple) from January of 2001 to December of 2020 (data from the web of science, January 2021). a Histogram of the number of papers in each field from 2001 to 2020; b A RhoA-FRET biosensor mouse was used to depict and quantify RhoA activity spatiotemporal distributions in native mammalian tissues in vivo during development and disease progression. Reproduced with permission from Ref. [80]. Copyright 2017, Elsevier; c Under laser excitation, a peptide biosensor with TCSPC-FLIM was utilized to monitor acetylation activity in real time. Reproduced with permission from Ref. [106]. Copyright 2019, American Chemical Society; d Representative color-coded image of NADH lifetimes in GSC tumor cells. Reproduced with permission from Ref. [36]. Copyright 2020, The International Society for Optical Engineering-SPIE. (Color figure online)

whereas Eq. (8) is used for multi-exponential decay. Multiexponential decay is suitable for complex fluorescence lifetime decay, particularly for the coexistence of different fluorophores.

$$
\begin{aligned}
& \mathrm{I}(\mathrm{t})=\mathrm{I}_{0} \exp \left(-\frac{\mathrm{t}}{\tau}\right) \\
& I(t)=\sum_{i} I_{o i} \exp \left(-\frac{t}{\tau_{i}}\right)
\end{aligned}
$$

$\left(I_{0}\right.$ : intensity at time $t=0 ; I_{01}$ : intensity at $t=0$ of each lifetime component; $\tau_{i}$ : fluorescence lifetime of each lifetime component).

As these two methods require the estimation of molecular species numbers of components, the fluorescence lifetime analysis is sometimes not accurate and convenient. A promising non-fitting analysis method the phasor analysis, was put forward, which avoids assuming mono- or multiexponential model to fit the data and is different in TD-FLIM and FD-FLIM [22]. In TD-FLIM, the fluorescence decays at each pixel $F(\mathrm{t})$ can be transformed into cosine $(\mathrm{g})$ and sine (s) coordinates in the phasor plot using Eqs. (9) and (10).

$g=\frac{\int_{0}^{\infty} F(t) \cos (\omega t) \mathrm{d} t}{\int_{0}^{\infty} F(t) d t}$

$s=\frac{\int_{0}^{\infty} F(t) \sin (\omega t) \mathrm{d} t}{\int_{0}^{\infty} F(t) \mathrm{d} t}$

where $\omega$ is the laser repetition angular frequency

If $F(\mathrm{t})$ is a single exponential decay, $\mathrm{g}$ and $\mathrm{s}$ can be calculated directly using Eqs. (11) and (12). 

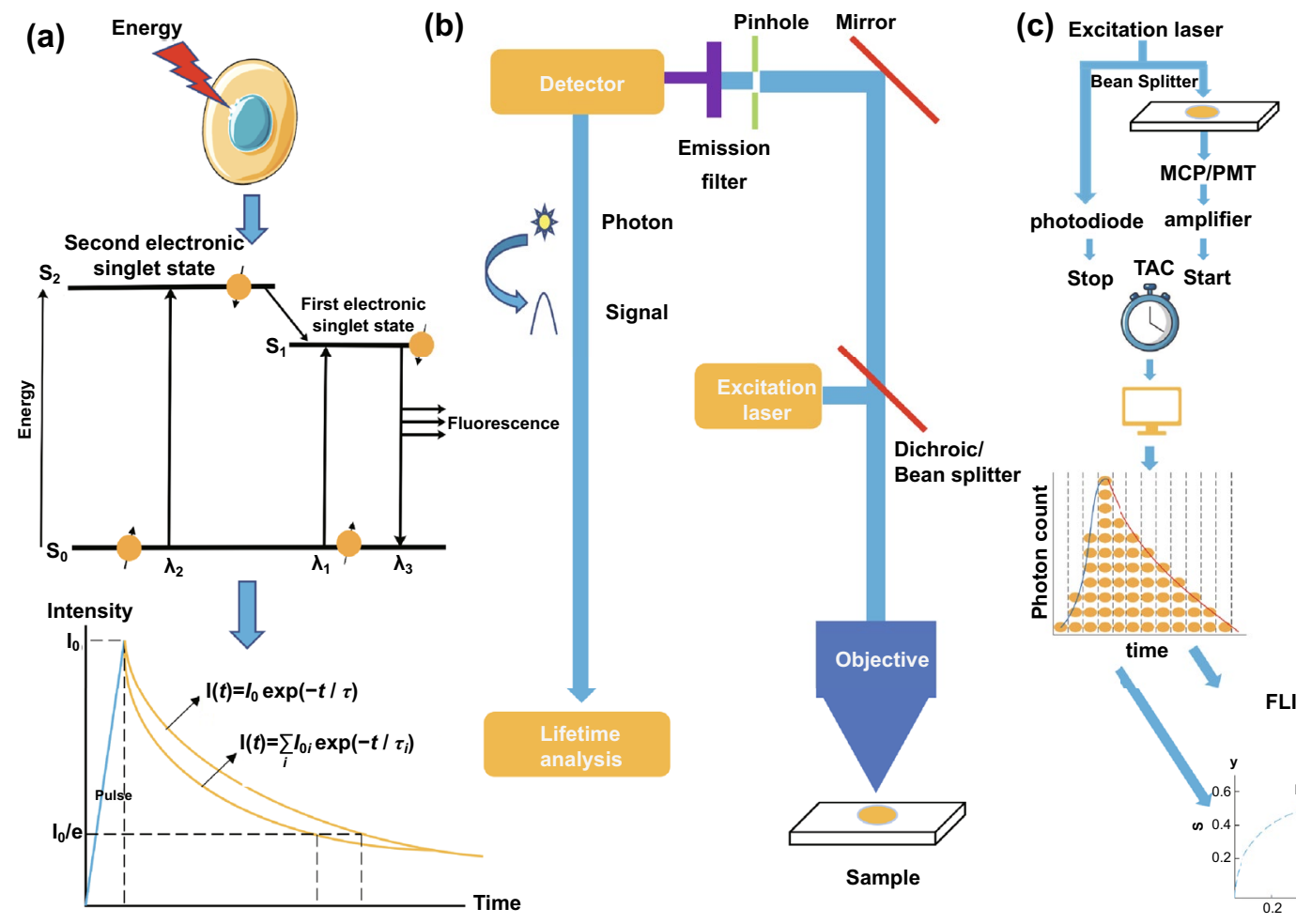

(d) Signal generator
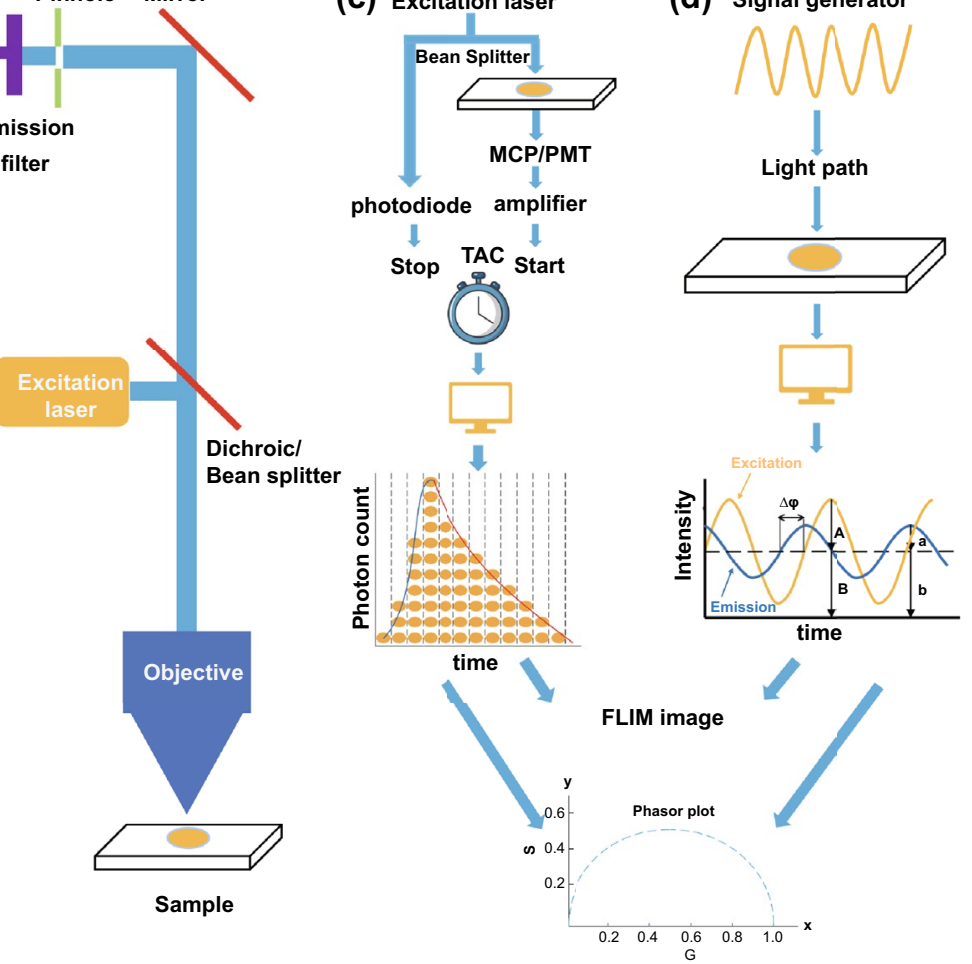

Fig. 2 Basic principles of fluorescence lifetime, fluorescence imaging, TCSPC-FLIM, and FD-FLIM. a Principles of fluorescence lifetime. b Basic setup for fluorescence imaging with a lifetime analysis instrument. $\mathbf{c}$ TCSPC-FLIM system scheme. d FD-FLIM sketch map

$g=\frac{1}{1+(\omega \tau)^{2}}$

$s=\frac{(\omega \tau)}{1+(\omega \tau)^{2}}$

As for the phasor analysis in FD-FLIM, the demodulation $\mathrm{M}$ and phase delay $\Delta \varphi$ are transformed into $\mathrm{g}$ and $\mathrm{s}$ coordinates using Eqs. (13) and (14) to represent a phasor vector on the plot.

$g=M * \cos (\Delta \varphi)$

$s=M * \sin (\Delta \varphi)$

Based on the phasor vector locations or clustering on the phasor plot, FLIM data can be analyzed according to several different point distribution types in the phasor plot. [23, 24]. For instance, a universal circle will be firstly constructed by $s=(g(1-g))^{1 / 2}$. The phasors of pixels with single-exponential or multi-exponential decay profiles will locate on or in the semi-circle, respectively. If there are two lifetime components, a "tie line" will connect the phasor locations of the two molecular species, where the relative positions of points on this line represent the relative contribution of these two species. In this manner, the molecular species number is easily ascertained, and color-coded FLIM can be performed.

\section{FLIM Combined with NAD(P)H for Cancer Metabolism Monitoring}

The reduced form of nicotinamide-adenine dinucleotide (i.e., NADH), nicotinamide-adenine dinucleotide phosphate (i.e., NADPH), and flavin adenine dinucleotide (i.e., FAD) are potent for metabolism monitoring based on their intrinsic fluorescence and the nonfluorescent characteristic of the reduced form of FAD (i.e., $\mathrm{FADH}_{2}$ ) and NAD. Besides, because of the identical spectral characteristics of NADH and NADPH, the acronym "NAD $(\mathrm{P}) \mathrm{H}$ " is frequently used [25]. 
The clinical applications of optical redox ratios, which can be calculated as FAD/[NAD $(\mathrm{P}) \mathrm{H}+\mathrm{FAD}]$, for oral and cervical cancer diagnosis have been discussed [26, 27]. However, due to the low quantum yield of NAD(P)H and FAD, the intensity-based method relying on optical redox ratios, is not as sensitive as we expect because of the background fluorescence interference. The fluorescence lifetime $\tau$ may hold promise for solving this deficiency. For lifetime measurement in NAD(P)H-FLIM research, bi-exponential decay is frequently applied to distinguish free and protein-bound cofactors [28]. The mean fluorescence lifetime $\tau_{\mathrm{m}}$ can be calculated using Eq. (12), and the fluorescence lifetime of free $\mathrm{NAD}(\mathrm{P}) \mathrm{H}$ is shorter than that of protein-bound $\mathrm{NAD}(\mathrm{P}) \mathrm{H}$, whereas free FAD possesses a longer fluorescence lifetime than protein-bound FAD [29].

$\tau_{m}=a_{1} \tau_{1}+a_{2} \tau_{2}$,

where $\tau_{1}$ and $\tau_{2}$ are the lifetime of short- and long-lifetime components with $a_{1}$ and $a_{2}$ as their relative contributions to the whole fluorescence.

Intensity and lifetime parameters possess respective advantages for different types of studies. Cancerous metabolic laboratorial and clinical studies have increasingly adopted lifetime index under the assistance of FLIM for $\mathrm{NAD}(\mathrm{P}) \mathrm{H}$ and FAD metabolism alteration detection. Figure 3 a presents a summary of this section.
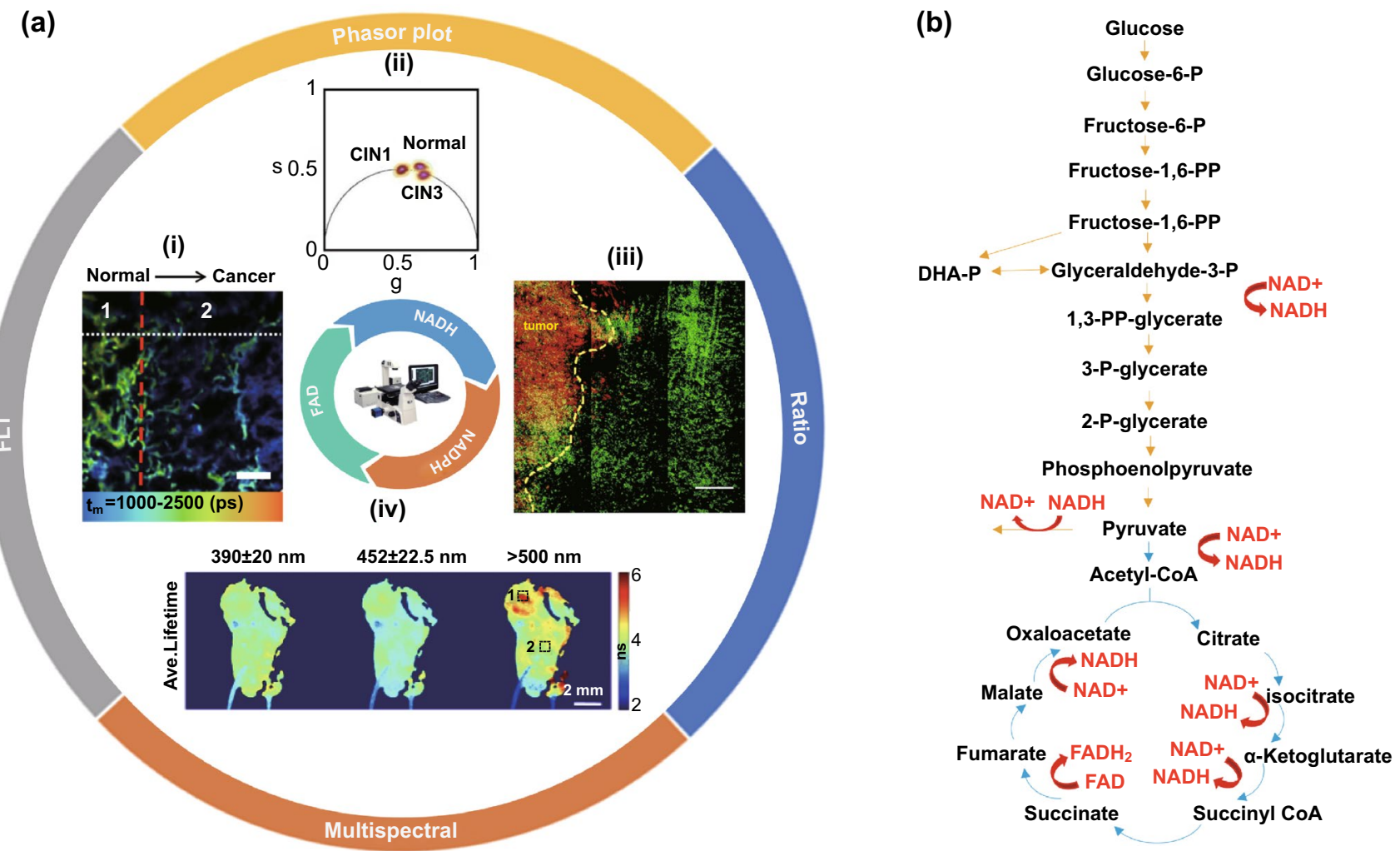

Fig. 3 An overview of the autofluorescence of NAD(P)H and FAD in FLIM applications to cancer research and NADH, FAD in core glucose metabolim (Glycolysis, TCA). a-i Fluorescence lifetime assists lung tumor resection. A clear fluorescence lifetime decrease is exhibited from the normal tissue to the cancer region. Reproduced with permission from Ref. [31]. Copyright 2017, Elsevier; a-ii Phasor FLIM plot is utilized for distinguishing the normal cervical tissue sample, CIN I sample, and CIN II sample. Reproduced with permission from Ref. [56]. Copyright 2020, Optical Society of America; a-iii NADH/NAD + ratio is applied for ascertaining tumor fronts. A clear higher NADH/NAD + ratio is exhibited in tumor cells (red) compared with CX3CR $1^{+/ g f p}$ monocyte cells (green). Reproduced with permission from Ref. [53]. Copyright 2020, Springer Nature; a-iv Fluorescence lifetime maps of ex vivo human oral biopsy by ms-FLIM. Region 1 and region 2 marked in the fluorescence lifetime map were diagnosed as superficial invasive squamous cell carcinoma and dysplasia, respectively. Reproduced with permission from Ref. [64]. Copyright 2014, Optical Society of America; b Scheme of NADH and FAD in TCA and glycolysis. Yellow arrows indicate glycolysis processes, and blue arrows represent the processes of TCA, whereas red arrows signify NADH or FAD participation. (DHA-P, dihydroxyacetone phosphate; CoA, coenzyme A). (Color figure online) 


\subsection{Fluorescence Lifetime}

As shown in Fig. 3b, glycolysis and tricarboxylic acid cycle (TCA) with oxidative phosphorylation (OXPHOS) are basic metabolic processes in which NADH and the reduced form of flavin adenine dinucleotide $\left(\mathrm{FADH}_{2}\right)$ are produced or consumed. Unlike normal cells, most cancer cells prefer glycolysis over OXPHOS as their glucose metabolism tends to produce less NADH and $\mathrm{FADH}_{2}$ as observed by Warburg in the last century [30]. Moreover, during OXPHOS, the produced NADH will bind to its coenzyme leading to its fluorescence lifetime increase from less than $0.4 \mathrm{~ns}$ in free-NADH conformation to $\sim 2 \mathrm{~ns}$ of its coenzyme-bound form. Therefore, the Warburg effect results in a significant decrease of fluorescence lifetime. For example, the average fluorescence lifetime in human lung cancer tissue is reduced, as indicated by the data in Fig. 3a-i [31]. The fluorescence lifetime in cancerous lung tissue is shorter than that in normal and tumor margin tissues, which can be applied to tumor resection. This reduction has also been verified in H-ras oncogene-transfected cancer cells (W31) and malignant thyroid tissue $[32,33]$. Various explanations for this effect have been proposed, including the proliferating cells' large requirements for nucleotides, amino acids, and lipids of cancer cells, as well as gene mutations [34]. Whereas, it should also be emphasized that the metabolism of some cancer cells is inconsistent with the Warburg effect, indicating that cancer cells may possess higher OXPHOS levels (contrary to the Warburg effect), including leukemia cells, glioblastoma stem cells (GSCs), and cerebrospinal fluid metastatic cells [35-37]. This abnormal phenomenon is common in cancer stem cells and metastatic cancer cells, and the deviation is relevant to different gene expressions and tumor microenvironments, such as hypoxia and lactic acidosis [38-41]. Additionally, the urgent energy needs, as opposed to huge substance requirements, for progression and metastasis in metastatic cancer cells may also lead to this abnormal effect. Overall, different cancer cells possess diverse metabolic profiles, indicating that simple therapies aimed at inhibiting tumor cell glycolysis or OXPHOS may not succeed and could even lead to easier occurrence. Fortunately, to evaluate cell apoptosis under specific treatments, FLIM has also been successfully applied to detect the metabolism change in non-tumorigenic cells (MCF10A), non-invasive cancer cells (MCF-7), and invasive cancer cells (MDA-MB-231) based on the fluorescence lifetime change $[42,43]$. Besides, under clinical conditions, the biopsy sample preservation conditions can be optimized using fluorescence lifetime monitoring [44]. For identifying gene mutation germlines, such as the BRCA mutation with the increased risk of developing breast cancer, fluorescence lifetime analysis is also helpful [45].

The fluorescence lifetimes of cancer-adjacent healthy tissues can also be applied to ascertain tumor boundaries, such as those of leiomyomas [46]. Additionally, a vital process called the reverse Warburg effect has been proposed. In this process, stromal cells produce energy-rich metabolites such as lactate through enhanced aerobic glycolysis, and cancer cells can convert these metabolites into pyruvate, providing fuel for the TCA cycle [47]. For example, disseminated breast tumor cells exhibit increased OXPHOS and increased fluorescence lifetimes compared to co-culture bone marrow stromal cells in the bone marrow niche [48]. However, not all tumor-stroma cell interactions conform to the reverse Warburg effect. One such exception is the metabolism in a HeLa-fibroblast co-cultivation system [49]. In addition to diagnostic applications, these observations have opened novel avenues for treatment.

Under some conditions, the long lifetime $\tau_{2}$ (boundNADH lifetime) is more sensitive, as indicated by the metabolic changes in breast cancer cells under glucose deprivation conditions [50]. Additionally, under enzymatic activity changes in glycometabolism, when using $10 \mu \mathrm{M}$ FX11-inhibiting lactate dehydrogenase (LDH) and $50 \mathrm{mM}$ dichloroacetate-relieving pyruvate dehydrogenase kinases (PDK) inhibition on the PDH of the cancer cells, the lifetime change is more obvious in $\tau_{2}$ group. Therefore, $\tau_{2}$ is more sensitive for monitoring carbon diversions compared to other parameters in this experiment [51].

\subsection{Ratios and Phasor Plots}

As NADH and FAD change their existence forms during glycolysis or OXPHOS, the ratios such as NADH/NAD + and free/bound NADH, are also promising for cancer metabolism monitoring. NADH/NAD + oxidation-reduction pairs are crucial for electron transfer in mitochondria, and NADH/ $\mathrm{NAD}+$ ratio is higher accompanied by enhanced anaerobic glycolysis [52]. As shown in Fig. 3a-iii, a higher NADH/ $\mathrm{NAD}+$ ratio in tumor cells with a lower ratio in monocyte/ macrophage cells can be applied for ascertaining tumor fronts, revealing that the fraction of anaerobic glycolysis in 
the tumor is larger than that in the surrounding monocytes or macrophages [53]. Besides, this NADH/NAD + ratio is relevant to free/bound $\mathrm{NAD}(\mathrm{P}) \mathrm{H}$ ratio based on previous researches, and the free/bound $\mathrm{NAD}(\mathrm{P}) \mathrm{H}$ ratio has been applied to melanoma progression detection [54]. Phasor plot is frequently applied for representing different free/boundprotein $\mathrm{NAD}(\mathrm{P}) \mathrm{H}$ ratios indicating alterations in cell metabolism under specific conditions, such as methionine stress or Wnt $/ \beta$ signaling inhibition [55]. As shown in Fig. 4a, FLIM phasor plot was constructed based on autofluorescence molecules such as free or bound NADH, elastin, and FAD. The colored lines between protein-bound and free NADH represent OXPHOS-to-glycolysis metabolism alteration. Furthermore, for clinical diagnosis, Phasor-FLIM has been successfully applied to cervical intraepithelial neoplasia (CIN) and neoplastic skin lesions, as shown in the phasor plot in Fig. 3a-ii [56]. This method is also adopted to glioblastoma multiforms (GBMs), leukemia subpopulation classification (Fig. 4b), as well as the identification of non-melanoma skin cancer (NMSC) [57-59]. Cancer metastasis is related to poor prognosis, and the original, first, and second metastatic cell lines (ZsG, LN1, LN2) can be distinguished by a free/bound NAD(P)H phasor plot [60]. Additionally, novel solutions for the chemo-resistance of cisplatin treatment have been proposed with the assistance from Phasor-FLIM [61]. Furthermore, a group of researchers introduced a novel redox ratio: Fluorescence Lifetime Redox Ratio (FLIRR), $\mathrm{NAD}(\mathrm{P}) \mathrm{H}-\mathrm{a}_{2} \%$ (enzyme-bound)/FAD $\mathrm{a}_{1} \%$ (enzyme-bound). In the OXPHOS course, the NAD(P)H-a ${ }_{2} \%$ (enzyme-bound) fraction will increase and the FAD $\mathrm{a}_{1} \%$ (enzyme-bound) fraction will decrease, resulting in the increase of FLIRR, which is sensitive to the metabolism change in the cells. This ratio was successfully combined with NAD(P)H-Trp FRET efficiency to monitor tumor and stroma cell metabolism, and predict doxorubicin treatment response [62, 63].

\subsection{Multi-parameter FLIM}

While lifetime and ratio indices are useful, multi-parameter combinations may yield even more useful data. Multispectral FLIM (ms-FLIM) applies to metabolism research based on NADH and FAD autofluorescence, which records FLIM images at multiple spectral bands. ms-FLIM is mostly applied in oral health research field, which was firstly adopted to distinguish the oral lesions from healthy tissue, as shown in Fig. 3a-iv [64]. With the development of ms-FLIM, it was applied to differentiate low-risk oral lesions, high-risk oral lesions, and oral carcinoma with high sensitivity and specificity in the hamster cheek pouch model [65]. The feasibility of msFLIM for early oral cancerous tissue detection was further testified by clinical trials [66, 67]. Besides, ms-FLIM dermoscopy system has been successfully constructed for discriminating basal cell carcinoma (BCC) from other dermatoses [68].

In addition to ms-FLIM, fluorescence lifetime analysis with other optic characteristics of substance to construct an improved classification model can also improve the accuracy of cancer diagnosis. For example, a three-dimensional classification model for differentiating glioblastoma (GBM) cells and metastasis cancer cells from control cells was constructed based on the redox ratio, second harmonic generation (SHG) intensity, and fluorescence lifetime, averaged for each tissue subgroup with a Gaussian ellipsoid fit [69]. Recently, another powerful method using a support vector machine (SVM) for classification based on the median, width, and entropy of lifetime $\tau_{2}$ was applied to breast cancer detection [70]. Similarly, as shown in Fig. 4c, by TCSPCTP-FLIM scanning hematoxylin- and eosin-stained biopsy samples, the Gaussian distribution, Shannon entropy, and fluorescence lifetime were used to construct SVM classification systems for distinguishing BCC from actinic keratosis (AK) and Bowen's disease (BD) [71].

Table 2 presents a summary of this section.

\section{FRET Combined with FLIM Applications}

\subsection{Intracellular FRET-FLIM Applications}

As an important energy transfer phenomenon, FRET has been applied in many research fields, especially in the protein interaction analysis $[72,73]$. The basic principle of FRET is that when the distance between a donor and acceptor is less than $10 \mathrm{~nm}$ with an overlapped spectrum, favorable dipole-dipole interactions, and sufficient quantum yield, the excitation of the fluorescence donor molecule can cause the acceptor molecule to emit fluorescence, after which the fluorescence intensity of the donor decreases rapidly, as shown in Fig. 5a [74, 75]. Therefore, FRET efficiency increases with a decreasing 

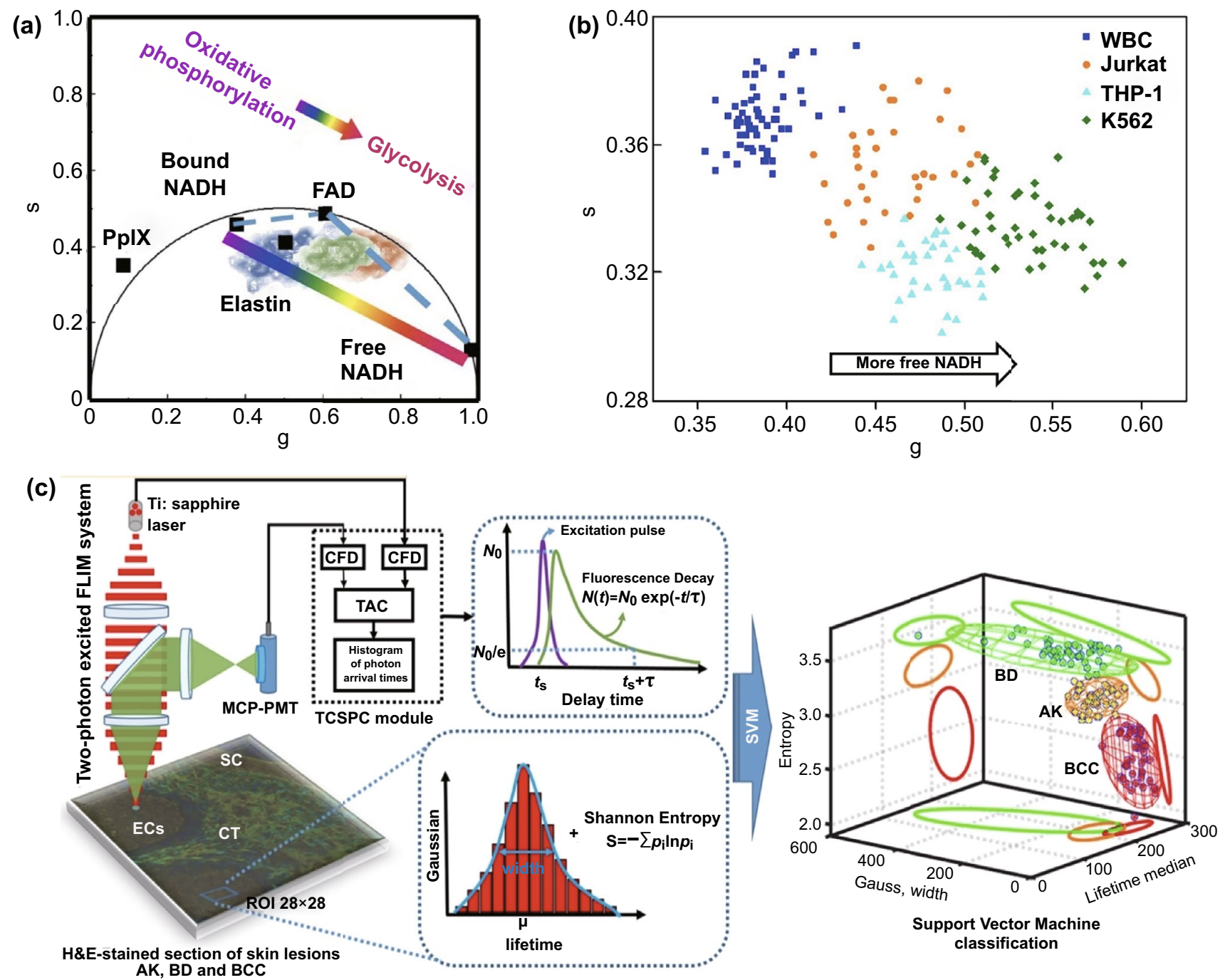

Fig. 4 Phasor plot and multi-parameter classification system based on autofluorescence molecules. a Representative phasor plot based on autofluorescence molecules in the cell. Reproduced with permission from Ref. [56]. Copyright 2020, Optical Society of American; b Scatter plot of 65 WBCs (blue), 35 Jurkat cells (orange), 46 K562 cells (green), and 35 THP-1 cells (cyan) based on NADH fluorescence signals. Lower $s$ values and higher $g$ values represent additional free NADH, indicating glycolysis metabolism trend, similar to that in a. Reproduced with permission from Ref. [58]. Copyright 2020, Frontiers Media S.A.; c Schematic map of an SVM classification system for evaluating the stages of non-melanoma skin cancers. Reproduced with permission from Ref. [71]. Copyright 2019, American Chemical Society. (Color figure online)

donor fluorescence lifetime, which can be detected by a total internal reflection fluorescent microscope (TIRF) or FLIM.

In FRET-FLIM experiments, both fluorescent proteins (FPs) and organic fluorophores can be applied as fluorescent labels functioned as FRET pairs for protein-protein interaction analysis, where FPs were mostly reported as an element of genetically encoded biosensors [76]. Different types of protein activities require diverse types of FRET pairs for detection, which is exhibited in Fig. 5. The cleavage FRET pairs can be used to detect caspase- 3 levels and treatment-induced apoptosis [77]. As shown in Fig. 5b, the active caspase- 3 will cleave the DEVD sequence, resulting in LSS-mOrange and mKate2 separation, leading to a FRET efficiency decreases with the lifetime of the donor (LSSmOrange) increases [78]. Additionally, a modified EGFP/ 
mRFP Raichu-RhoA biosensor successfully observed the up-regulation of RhoA activity, which is related to numerous cellular activities and is known to drive cell motility in invasive cancers [79]. As shown in Fig. 5c, RhoA binds to GDP and exhibits non-FRET confirmation, whereas FRET confirmation appears when RhoA binds to GTP. Through FRET efficiency analysis, the activity of RhoA in tissue can be detected [80]. Various FRET biosensors for the detection of cancer-metabolism-related proteins, such as adenosinemonophosphate-activated protein kinase, have also been reported [81, 82]. Besides, cancers can also be induced by disturbed signal pathways. For example, in the FRET pairs in Fig. 5d, a high FRET efficiency between the labeling tags on protein kinase $\mathrm{B}$ (PKB) can be observed in the metastatic clear cell renal cell carcinoma sample, which is practical for predicting patient survival and optimizing personalized therapy. When the activation state of PKB/Akt increases, PKB will exhibit conformational change leading to FRET between the serine and threonine fluorescent labeling. The donor lifetime decreases, which can be recorded by FLIM [83]. In addition to the PKB/Akt signaling pathway, phospholipid signaling pathways are also involved in breast cancer. A novel phosphatidic acid (PA) biosensor called PASS has been successfully applied to the detection of the spatiotemporal production of PA, which is a type of phospholipid, based on decreased donor lifetimes [84]. Furthermore, posttranslational protein modification aberrations are also relevant to cancer occurrence and progression. Taking Poly(ADP-ribose)ylation (PARylation) as an example, PARylation can be monitored by using FRET-FLIM to assist in the PARylation dysregulation detection of cancer cells [85].

Regarding anti-cancer treatment, the capabilities of FRET-FLIM for drug validation have also been demonstrated [86]. For example, FRET-FLIM revealed the close distance between translation elongation factor eEF1A2 and an anti-tumor agent, plitidepsin, forming a drug-protein complexes in tumor cells [87]. Besides, for novel drug discovery and development, FRET-FLIM has been used to discover interaction domains between nuclear epigenetic integrators and their partners, as well as potential histone epigenetic therapeutic targets [88, 89]. Similarly, an unexpected sequence involved in the binding domain between anti-apoptosis and pro-apoptosis/BH3 proteins was found using FRET-FLIM, opening a new avenue for enhancing the combination of $\mathrm{BH} 3$ mimetic drugs and anti-apoptotic proteins for cancer treatment [90]. Additionally, for choosing superior treatment options, FRET-FLIM can provide important references by evaluating Src activity. As shown in Fig. 5f, once active Src phosphorylates the substrate, the biosensor will exhibit non-FRET confirmation. If dephosphorylation happens due to phosphatases, it will transform into the FRET confirmation [91]. In addition to these applications, a hot-FRET-based anti-cancer therapy called photodynamic therapy (PDT) also deserves attention. Based on material innovations, fluorescence lifetime imaging and PDT can be achieved in a single material, such as 3 -aminophthalic acid [92]. Furthermore, this type of therapy can be improved through monitoring using sensitizer phosphorescence lifetime imaging and FLIM [93].

\subsection{FRET-FLIM for Cancer Cell Membrane Receptor Detection}

In addition to protein interactions within cells, the receptors on membranes are also important biomarkers for cancer diagnosis. Traditionally, FLIM with a specific probe has been utilized to detect receptor expression levels, such as chemokine receptor 4 and human epidermal growth factor receptor 2 (HER2) [94, 95]. Recently, FLIM was combined with FRET pairs for membrane receptor detection. Among abundant receptors, the ErbB receptor family, including EGFR, HER2 and HER3, is considered to be one of the "superstar" families.

The ErbB receptor family participates in both signal conduction and cell proliferation and its abnormal content or activity is considered to be relevant to cancer initiation, progression, and treatment prognosis [96, 97]. By using FRETFLIM, the HER2-HER3 dimer level has been detected by analyzing the fluorescence lifetime of HER3 fluorophore dye. As shown in Fig. 5e, FRET occurs between Alexa546 loaded onto HER3 (donor) and Cy5 loaded onto HER2 (acceptor), resulting in a decrease in the Alexa546 fluorescence lifetime [98]. Furthermore, the significant intratumor heterogeneity of epidermal growth factor receptor (EGFR) activity influences drug function. This has been monitored by novel FRET pairs of eGFP and mRFP1 based on the conformation change phenomenon because of Tyr 
Table 2 NAD(P)H \& FLIM

\begin{tabular}{|c|c|c|c|c|c|c|c|}
\hline \multirow{2}{*}{$\begin{array}{l}\text { Parameters } \\
\text { FLT }\end{array}$} & \multicolumn{3}{|l|}{ Comparative group } & \multicolumn{2}{|c|}{ Result } & \multirow{2}{*}{$\frac{\text { Research goal }}{\text { Lung cancer tissue detection }}$} & \multirow{2}{*}{ Refs. } \\
\hline & Lung cancer tissue & Healthy tissue & & $<$ & & & \\
\hline & W31(cancer cells) & WFB & & $<$ & & Cancer cell detection & {$[32]$} \\
\hline & GSCs & NSCs & & $>$ & & $\begin{array}{l}\text { Metabolic profile change } \\
\text { in GSCs }\end{array}$ & [36] \\
\hline & GBM tissue & Normal mouse brain tissue & & $>$ & & $\begin{array}{l}\text { GBM tissue metabolic flux } \\
\text { detection }\end{array}$ & {$[36]$} \\
\hline & CSF-metastatic cell & Inflammatory cell & & $>$ & & $\begin{array}{l}\text { CSF-metastatic cell identi- } \\
\text { fication }\end{array}$ & {$[37]$} \\
\hline & $10 \%$ BSA on ice condition & Control & & $\approx$ & & $\begin{array}{l}\text { Best preserved condition for } \\
\text { cancer biopsy diagnosis }\end{array}$ & [44] \\
\hline & Malignant thyroid lesions & Benign lesions & Healthy thyroid & $>$ & $\approx$ & $\begin{array}{l}\text { Malignant thyroid lesion } \\
\text { detection }\end{array}$ & [33] \\
\hline & BRCA2 mutation carrier & BRCA1 mutation carrier & Normal Lymphocyte cell & $<$ & $\approx$ & $\begin{array}{l}\text { High cancerous risk gene } \\
\text { mutation cell line detec- } \\
\text { tion }\end{array}$ & {$[45]$} \\
\hline \multirow[t]{2}{*}{ NAD(P)H lifetime $\tau_{2}$} & Glucose deprivation group & Control & & $>$ & & $\begin{array}{l}\text { Glucose deprivation in } \\
\text { breast cancer cell detec- } \\
\text { tion }\end{array}$ & {$[50]$} \\
\hline & $\begin{array}{l}\text { LDH, PDK enzyme inhibi- } \\
\text { tion }\end{array}$ & Control & & l & & $\begin{array}{l}\text { Key enzymatic steps inhibi- } \\
\text { tion monitoring }\end{array}$ & {$[51]$} \\
\hline $\mathrm{NADH} / \mathrm{NAD}+$ & Tumor cell & Monocyte/Macrophage cell & & $>$ & & Tumor front delineation & {$[53]$} \\
\hline FLIRR & Doxorubicin treatment & Pre-treatment & & $>$ & & $\begin{array}{l}\text { Doxorubicin treatment } \\
\text { assessment }\end{array}$ & {$[62]$} \\
\hline \multirow[t]{8}{*}{ Free/bound NADH } & HeLa & Fibroblast & & $\uparrow$ & $\downarrow$ & $\begin{array}{l}\text { Tumor-fibroblasts metabo- } \\
\text { lism interaction }\end{array}$ & [49] \\
\hline & $\begin{array}{l}\text { Metastatic B16F10 mela- } \\
\text { noma }\end{array}$ & Pre-progression melanoma & & $>$ & & $\begin{array}{l}\text { Melanoma detection and } \\
\text { staging }\end{array}$ & {$[54]$} \\
\hline & Wnt $/ \beta$ signaling inhibition & Control & & $<$ & & $\begin{array}{l}\text { The relationship of Wnt/ } \beta \\
\text { signaling and tumor } \\
\text { metabolic phenotype }\end{array}$ & {$[55]$} \\
\hline & STIC & TMF & & $<$ & & $\begin{array}{l}\text { Classification of GBM } \\
\text { subpopulation }\end{array}$ & {$[57]$} \\
\hline & REV3L absence group & Control & & $<$ & & $\begin{array}{l}\text { A novel approach to mini- } \\
\text { mize chemo-resistance of } \\
\text { cisplatin treatment }\end{array}$ & {$[61]$} \\
\hline & CIN1 & CIN2 & CIN3 & $\approx$ & $<$ & $\begin{array}{l}\text { Cervical intraepithelial } \\
\text { neoplasia grade }\end{array}$ & {$[56]$} \\
\hline & ZsG & LN1 & LN2 & $\approx$ & $>$ & $\begin{array}{l}\text { Metastatic oral squamous } \\
\text { carcinoma cell detection }\end{array}$ & {$[60]$} \\
\hline & $\mathrm{BCC}$ & $\mathrm{AK}$ & $\mathrm{BD}$ & l & & $\begin{array}{l}\mathrm{BCC}, \mathrm{AK} \text {, and BD distin- } \\
\text { guishment }\end{array}$ & [59] \\
\hline \multirow[t]{2}{*}{ SVM } & Adipose tissue & Fibrous tissue & Breast cancer tissue & l & & $\begin{array}{l}\text { Adipose, fibrous, and breast } \\
\text { cancer tissue distinguish- } \\
\text { ment }\end{array}$ & {$[70]$} \\
\hline & $\mathrm{BCC}$ & $\mathrm{AK}$ & $\mathrm{BD}$ & l & & $\begin{array}{l}\mathrm{BCC}, \mathrm{AK} \text {, and } \mathrm{BD} \text { distinc- } \\
\text { tion }\end{array}$ & [71] \\
\hline
\end{tabular}

$" \approx<>$ " represents absolute parameters value between adjacent two groups (from left to right); " $\uparrow$ " symbolizes parameter increase or decrease GSCs Glioblastoma stem cells, NSCs Neural stem cells, GBM glioblastoma multiforme, CSF cerebrospinal fluid, BSA bovine serum albumin, $L D H$ lactate dehydrogenase, $P D K$ pyruvate dehydrogenase kinase, STIC stem-like tumor-initiating cells, $T M F$ tumor mass-forming cells, $B C C$ basal cell carcinoma, $A K$ actinic keratosis, $B D$ Bowen's disease

phosphorylation using FLIM [99]. Similarly, by utilizing Alexa 546 and DyLight 649 labeled antibodies, FRET/FLIM has been applied to determine Gefitinib phosphorylation statuses for modulating the stability of EGFR dimers, providing a novel method for cancer-targeted therapy to deregulate EGFR signaling [100].

Previous studies on FRET-FLIM are summarized in Table 3. 


\section{FLIM Combined with Fluorophore Dye Probes}

\subsection{Intracellular Molecule Change Detection}

Traditionally, the intensity method using fluorescent probes with FLIM has been very common. This method is based on over-expression receptors or molecules in cancer cells, such as Dmt-Tic-IR800 probes targeting overexpressed delta-opioid receptors in lung cancer cells and gold nanoclusters aimed at high glutathione levels in cancer cells [101, 102]. The fluorescence lifetime method is another promising technique for cancer diagnosis and treatment improvement.

In the nuclei of cells, the DNA binder, DAPI, has been combined with FLIM to detect two common aberrations in B-cell chronic lymphocytic leukemia (B-CLL) and acute lymphoblastic leukemia (B-ALL). Specifically, an extra $12^{\text {th }}$ chromosome and the deletion of p53 can be detected based on different lifetime changes [103]. Furthermore, a tripodal cationic fluorescent probe, called NBTE, has been combined with FLIM to detect G-Quadruplex. Based on the distinctive fluorescence lifetime response of G-Quadruplex, the content of DNA G-Quadruplex in lung, mammary and hepatic cancer cells is four times than that in normal cells, which can be exploited for cancer diagnosis [104]. Similarly, another G-Quadruplex fluorescent probe called o-BMVC foci, has also been used to identify G-Quadruplex motifs in combination with FLIM [105]. In addition to G-Quadruplex, the acetylation of histone lysine residues of acetyltransferase is another target for anti-cancer drugs that can be monitored by using a P300/CBP associated factor (PCAF) biosensor (HATS) in combination with FLIM (Fig. 6b). After the

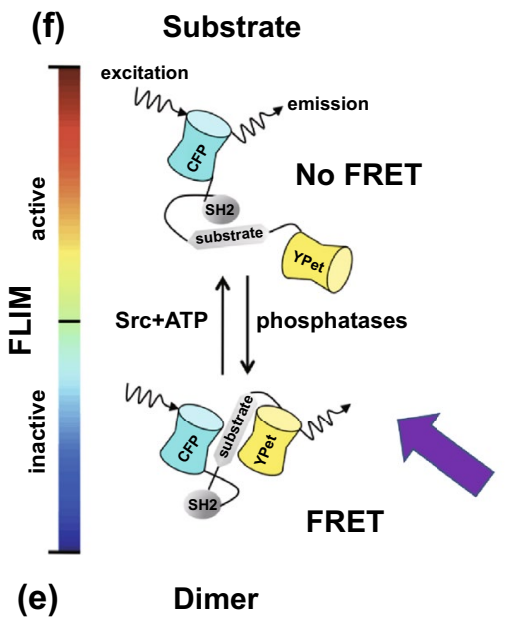

(e) (b) Cleavage

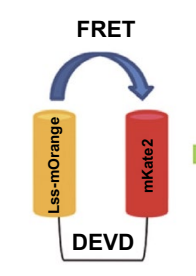

(a)
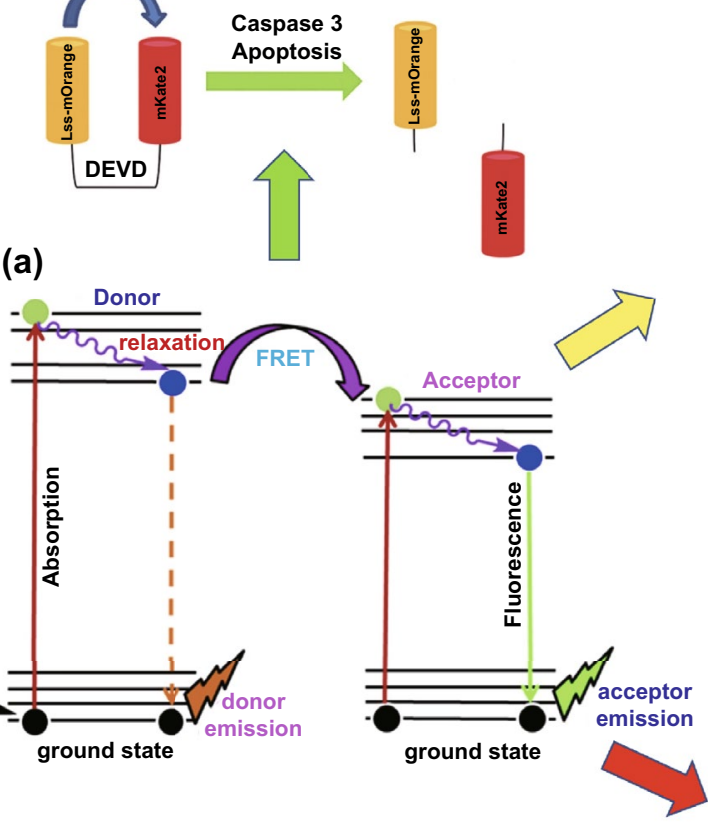

(c) Binding domain
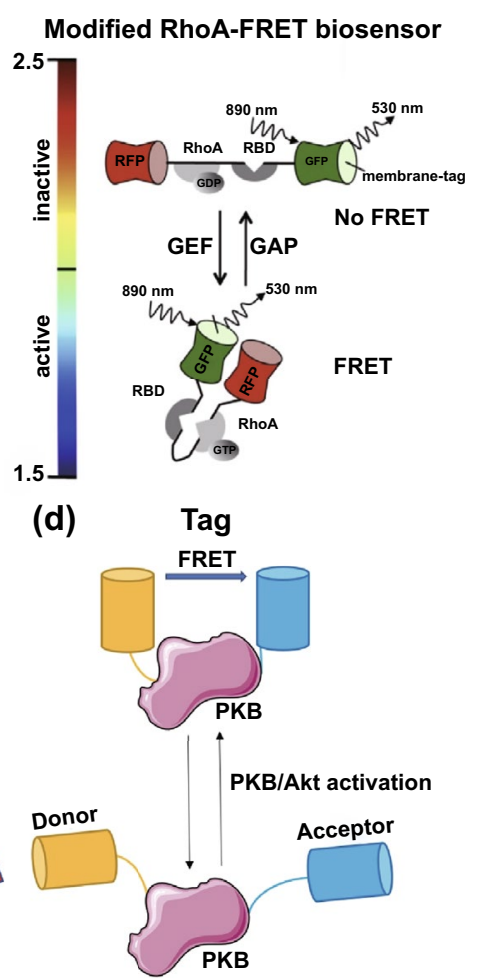

Fig. 5 FLIM in combination with FRET for cancer diagnosis and treatment improvement. a Scheme of the FRET mechanism between an electron donor and receptor. Reproduced with permission from Ref. [75]. Copyright 2018, Elsevier; b Cleavage type: LSS-mOrange and mKate2 connected by an aspartate-glutamate-valine-aspartate (DEVD) linkage sequence for caspase-3 activity detection. Reproduced with permission from Ref. [77]. Copyright 2015, MDPI; c Binding domain type: Raichu-RhoA biosensor. Reproduced with permission from Ref. [80]. Copyright 2017, Elsevier; d Protein tag type: PKB tag biosensor for PKB activation state detection. e Dimer type: HER2-HER3 dimer for quantifying HER2-HER3 dimer. Reproduced with permission from Ref. [98]. Copyright 2016, Impact Journals; f Substrate type: FRET-based Src biosensor. The FLIM-bar indicates the Src activity from Src active (red to yellow) to inactive colors (green to blue). Reproduced with permission from Ref. [91]. Copyright 2014, Taylor \& Francis. (Color figure online) 
sensor binds to the histone acetyltransferase (HAT) target, upon acetylation, phosphor-lysine will be incorporated with the PCAF bromodomain, resulting in an increase of the fluorescence lifetime of the reporter [106].

Regarding research on the cytoplasm, the lifetime of the fluorescence dye ATTO425 on the aptamer AS1411 is shorter in cancer cells than that in normal cells [107]. Additionally, intracellular glucose levels can be detected based on the fluorescence lifetimes of aminophenyl boronic acid (APBA)-modified CdSe/ZnS quantum dots (QDs) (QDAPBA). As shown in Fig. 6a, when QD-APBA conjugates bind to glucose, there is an evident increase in lifetime compared to the control group, which can be detected by FLIM [108]. In addition to glucose consumption, Fig. 6c also shows that a $\pi$-extended fluorescent coumarin (PC6S) combined with FLIM can be successfully applied for lipid droplet imaging related to lipid metabolism [109]. As glucose and lipid metabolism are both relevant to cancer cells' activities, these strategies are promising for cancer diagnosis and anti-cancer treatment efficiency elevation.

\subsection{FLIM-probe Applications to Cellular Membrane Structures}

\subsubsection{Membrane Potential}

In the field of studying membranes, a lack of non-invasive and sensitive tools for measuring absolute membrane voltage $\left(V_{\text {mem }}\right)$ restricts the understanding of the cellular activities behind cancer. Specific fluorescent dyed probes in combination with FLIM can be used to detect membrane potentials. For example, voltage Fluor dyes with FLIM have successfully detected membrane potentials based on longer lifetimes related to membrane potential depolarization, as shown in Fig. 7a, where one can see a positive linear relationship between lifetime and membrane potential [110]. Similarly, for the detection of mitochondrial membrane potential, green- and orange-emitting fluorescent dyes (SYTO) and tetramethylrhodamine methyl ester (TMRM) acting as FLIM probes have been applied to monitor mitochondrial membrane potential (MMP) changes, which was based on shorter lifetime related with enhanced mitochondrial polarization due to the quenching of fluorophores. The capability of these two fluorescent dyes for MMP detection was also testified in cancer cells and organoids [111]. Furthermore, the negative mitochondrial membrane potentials in cancer cells are important biomarkers that can be exploited to accumulate cytotoxic cationic molecules for anti-cancer treatment. The corresponding treatment outcomes can be analyzed using Phasor-FLIM [112, 113].

\subsubsection{Membrane Viscosity}

It is known that membrane viscosity affects membrane permeability, enzymatic activity, and other factors. Abnormalities are associated with malignant transformations, which can be detected by membrane viscosity probes mostly based on boron-dipyrromethene (BODIPY) structures, as shown in the left panel of Fig. 7b [114]. Based on the right panel of Fig. 7b, the fluorescence lifetimes of probes will increase under higher-viscosity conditions because the higher-viscosity leads to increasing transformation energy barrier between the planar conformation and the butterfly conformation of the BODIPY rotor, which impedes non-radiative decays.

In vitro, BODIPY in combination with FLIM has already achieved the quantitative measurement of viscosity in tumor cell spheroids and viscosity changes in cisplatin-treated tumor cells $[115,116]$. To facilitate clinical applications, the improved fluorescent molecular rotors BODIPY1 and BODIPY2 have been combined with FLIM to accomplish in vivo viscosity monitoring. In an assay of viscosity imaging in CT26 subcutaneous tumors in vivo, Fig. 7c demonstrates that BODIPY 2 rotors can be dislodged in a tumor, providing a sensitive and non-invasive method for detecting viscosity. For BODIPY time-resolved fluorescence decay, only mono-exponential decay is usable for lifetime/viscosity calibration, but biexponential results cannot be utilized because of the quenching of BODIPY aggregates. It is clear that mono-exponential decay is exhibited by the tumor cells and connective tissue, demonstrating that BODIPY2 is capable of in vivo viscosity imaging [117].

\subsection{FLIM Applications to the Extracellular Environments of Cancer Cells}

In combination with a well-designed fluorescent biosensor, FLIM can be utilized to monitor cancer milieu, such as the quantitative measurement of $\mathrm{pH}$ in engineered tissues based on the fluorescence lifetimes of novel biosensors, as shown 
Table 3 FRET \& FLIM

\begin{tabular}{|c|c|c|c|c|c|c|c|}
\hline \multirow[t]{2}{*}{ Target molecule } & \multirow[t]{2}{*}{ FRET type } & \multicolumn{2}{|l|}{ FRET pairs } & \multirow[t]{2}{*}{ FLIM } & \multicolumn{2}{|l|}{ Potential application } & \multirow[t]{2}{*}{ Refs. } \\
\hline & & Donor & Acceptor & & Molecular & Clinical & \\
\hline $\operatorname{Trp}$ & Dimer & $\operatorname{Trp}$ & $\mathrm{NAD}(\mathrm{P}) \mathrm{H}$ & TCSPC-FLIM & $\begin{array}{l}\text { Bound NAD }(\mathrm{P}) \mathrm{H} \\
\text { detection }\end{array}$ & $\begin{array}{c}\text { Drug response } \\
\text { evaluation }\end{array}$ & {$[63]$} \\
\hline Caspase 3 & Cleavage & LSS-mOrange & mKate2 & FD-FLIM & $\begin{array}{l}\text { Apoptosis level } \\
\text { detection }\end{array}$ & Drug evaluation & {$[77,78]$} \\
\hline RhoA & Binding domain & EGFP & mRFP-Raichu & TCSPC-FLIM & $\begin{array}{l}\text { RhoA activity level } \\
\text { detection }\end{array}$ & $\begin{array}{l}\text { Invasive subtype } \\
\text { identification }\end{array}$ & {$[80]$} \\
\hline PKB & Tag & panAkt & pT308 & FD-FLIM & $\begin{array}{l}\text { PKB activation } \\
\text { state detection }\end{array}$ & $\begin{array}{l}\text { Personalized } \\
\text { therapy }\end{array}$ & {$[83]$} \\
\hline $\begin{array}{l}\text { Phosphatidic Acid } \\
\text { (PA) }\end{array}$ & Binding domain & GFP-tH/GFP-tK & RFP-PASS & FLIM & $\begin{array}{l}\text { PA production and } \\
\text { function detec- } \\
\text { tion }\end{array}$ & I & [84] \\
\hline PARylation & Dimer & EGFP-ARTD1 & $\begin{array}{l}\text { TMR labeled } \\
\text { NAD + analog }\end{array}$ & FLIM & $\begin{array}{l}\text { PARylation level } \\
\text { detection }\end{array}$ & $\begin{array}{l}\text { Cancer diagnosis } \\
\text { \& Drug evalu- } \\
\text { ation }\end{array}$ & {$[85]$} \\
\hline eEF1A2 & Dimer & DMAC & GFP & FD-FLIM & $\begin{array}{l}\text { eEF1A2-plitidep- } \\
\text { sin interaction } \\
\text { detection }\end{array}$ & l & [87] \\
\hline UHRF1 & Dimer & eGFP & mCherry & TCSPC-FLIM & l & $\begin{array}{l}\text { MYST60 domain } \\
\text { knockdown for } \\
\text { cancer treatment }\end{array}$ & [88] \\
\hline ER & Dimer & ALEXA488 & ALEXA546 & TCSPC-FLIM & $\begin{array}{l}\text { Epigenetic thera- } \\
\text { peutic targets } \\
\text { detection }\end{array}$ & $\begin{array}{l}\text { Drug combination } \\
\text { therapy }\end{array}$ & [89] \\
\hline Bim & Dimer & mCer3 & Venus & TCSPC-FLIM & l & $\begin{array}{l}\text { BH3 mimetic drug } \\
\text { improvement }\end{array}$ & [90] \\
\hline Src & Substrate & ECFP & YPet & FLIM & $\begin{array}{l}\text { Src activity detec- } \\
\text { tion }\end{array}$ & $\begin{array}{l}\text { Drug combination } \\
\text { strategy evalu- } \\
\text { ation }\end{array}$ & [91] \\
\hline HER2 & Dimer & Alexa546 & Cy5 & TCSPC-FLIM & $\begin{array}{l}\text { HER2-HER3 } \\
\text { dimer level } \\
\text { detection }\end{array}$ & Drug evaluation & [98] \\
\hline EGFR & Substrate & eGFP & mRFP1 & TD-FLIM & $\begin{array}{l}\text { EGFR heteroge- } \\
\text { neity }\end{array}$ & $\begin{array}{l}\text { EGFR targeted } \\
\text { treatment } \\
\text { improvement }\end{array}$ & [99] \\
\hline EGFR & Tag & Alexa 546 F4 & DyLight 649 F4 & TCSPC-FLIM & $\begin{array}{l}\text { Influence factor } \\
\text { of EGFR dimer } \\
\text { stability }\end{array}$ & $\begin{array}{l}\text { Novel EGFR tar- } \\
\text { geted anti-cancer } \\
\text { therapy }\end{array}$ & {$[100]$} \\
\hline EGFR & Dimer & Alexa 546 F4 & Cy5 2F12 & TD-FLIM & $\begin{array}{l}\text { Exosomes' recep- } \\
\text { tors heterogene- } \\
\text { ity detection }\end{array}$ & I & [121] \\
\hline
\end{tabular}

FLIM Fluorescence lifetime imaging microscopy, TD-FLIM time-domain FLIM, FD-FLIM frequency domain FLIM, TCSPC-FLIM time-correlated single photon counting FLIM

Footnotes: "FLIM" means the article did not mention specific time-domain or frequency-domain FLIM

in Fig. 8a, where a cellulose-binding domain (CBD) is fused with a $\mathrm{pH}$-sensitive enhanced cyan fluorescent protein (ECFP) [118]. As cancer cells' glycolysis metabolic trends leading to the reduced $\mathrm{pH}$ in cancer microenvironment, which reforms extracellular matrix for cancer metastasis,
FLIM is promising for cancer progression and metastasis research. Additionally, the vascular morphology of tumor tissue is another important topic. An anionic ultra-small QD with an ultra-long fluorescence lifetime has successfully realized vascular imaging in normal and cancerous tissues in 
combination with FLIM. As shown in Fig. 8b, the neogenic vessels in tumor tissue are tortuous and disordered [119].

Outside of cells, exosomes, which exhibit number, size, and receptor heterogeneity, should not be neglected. Similar to cell membrane alteration detection, a rapid tumor diagnosis tool based on the combination of a membranetargetable viscosity probe, called Mem-BDP, and FLIM, has been proposed to analyze membrane viscosity. Figure $8 \mathrm{c}$ demonstrates that larger exosomes originating from different cancer cells possessing lower viscosity result in a shorter fluorescence lifetime [120]. In addition to exosome size, the EGFR heterogeneity on oncosomes' membrane can also be detected by FRET-FLIM based on the FRET occurrence between antibodies Cy52F12 on HER3 and Alexa 546 F4 on EGFR. Through this strategy, the oncogenic receptor signal rewiring was revealed which was helpful for optimizing anti-cancer treatments. [121] However, thus far, no methods based on the lifetime dimension have been reported for quantifying exosomes, meaning this area requires further investigation.

A summary of Sects. 5.1, 5.2, and 5.3 is presented in Table 4.

\subsection{Fluorescence Anti-cancer Drugs with FLIM for Drug Delivery Research}

Fluorescence drugs or fluorescent-dyed drug carriers combined with FLIM are useful tools for drug delivery. In a previous study, emission wave changes in drug fluorescence caused by conformational alteration were applied to analyze delivery processes [122]. However, the fluorescence wave changes indicated by light color shifts were not as sensitive as desired, but fluorescence lifetime may be a promising solution for sensitivity improvement. For example, different entry pathways for exosomes (EXOs) and microvesicles (MVs) can be investigated using the method shown in Fig. 9a. By using Oregon green (OG)-labeled paclitaxel (Ptx) loaded onto EXOs and MVs, and based on fluorescence lifetime differences, FLIM can determine that exosomes deliver drugs via endocytosis, whereas most microvesicles enter cells via both endocytosis and fusion with cell membranes [123].

Liposomal-based anti-cancer drug delivery systems are capable of delivering fluorescent anti-cancer drugs such as doxorubicin and curcumin using FLIM for process monitoring. As shown in Fig. 9b, the first obstacle to liposome drug delivery is dynamic biomolecular corona (BC) formation in vivo, which changes the original liposome synthetic identities, leading to drug leakage. While Doxoves ${ }^{\circledR}$ was selected as a control group following exposure to human plasma (HP), Doxoves ${ }^{\circledR}$ was surrounded by complex BC that changed the liposome's synthetic identity. The corresponding FLIM images of Doxoves ${ }^{\circledR}$ (left panel) and Doxoves ${ }^{\circledR}-\mathrm{HP}$ complexes $(\mathrm{HP}=50 \%$, right panel) in a $1.7 \%$ agarose gel (bottom two images) demonstrated that the failure of DOX delivery was relevant to the rupture of the membrane and drug release in a physiological environment [124]. Furthermore, FLIM has also been employed to investigate the mechanisms behind the low nuclear internalization efficiencies of drug delivery patterns such as liposomal doxorubicin (L-Dox), thereby increasing their clinical utility [125].

In addition to liposomal-based methods, numerous novel nanomedicine delivery systems have also been constructed, where FLIM mainly functions as an auxiliary monitoring apparatus [126]. An experiment using free Dox and Au-Dox was performed on melanoma B16 cells and cardiomyocytes. FLIM revealed that while Au-Dox entered the nuclei of the B 16 cells, only free Dox could enter the nuclei of the cardiomyocytes, indicating that Au-Dox has reduced toxicity to normal cells [127]. Another promising DOX delivery system, called DOX-loaded graphene oxide (GO) or GO-DOX, has exhibited much higher anti-cancer efficiency than L-DOX. FLIM determined that the mechanism behind this improvement was that GO-DOX bound to cell plasma membranes to induce massive intracellular DOX release [128]. Additionally, a novel DOX delivery system, called PAH-Cit-Dox, has also been constructed, as shown in Fig. 9c. The DOX release and intracellular distribution were analyzed by Phasor-FLIM and phasor-differentiated lifetime pixel intensity in Fig. 9d. Based on the diverse fluorescence lifetimes of DOX, MCF-7 cells were separated into four sections of cell membranes, cytoplasm, nucleus membranes, and nucleus in the phasordifferentiated lifetime pixel intensity image [129]. Similarly, a novel $\mathrm{pH}$-sensitive nano-chemotherapeutic system, called AuNPs@gelatin-hyd-Dox, was synthesized for tracking the release and intracellular kinetics of Dox and Au-NPs by detecting fluorescence signals and photoluminescence using TP-FLIM [130]. Furthermore, FLIM has successfully detected a novel hybrid probe internalization pathway used for drug delivery (consisting of $\beta$-D-glucan and the boronic 
(a)
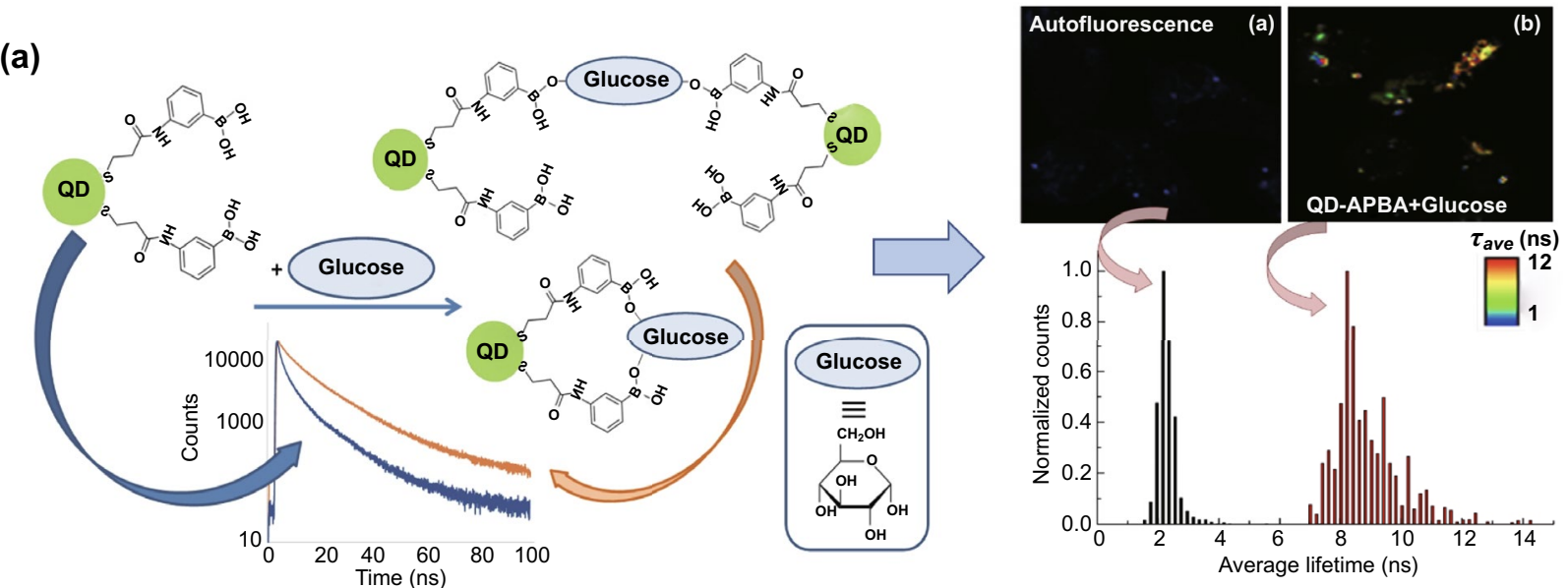

(b)

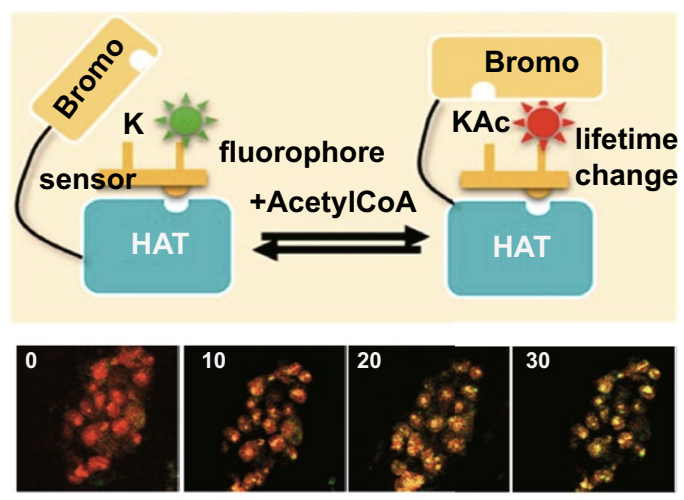

0 Fluorescence lifetime (ns) 3.8 (c)
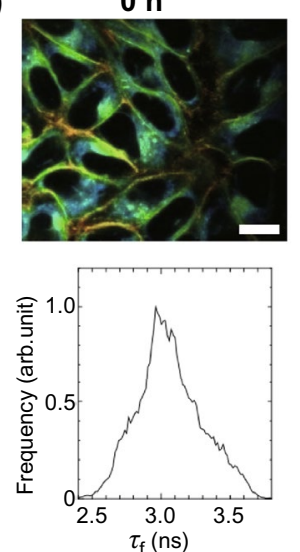

$24 \mathrm{~h}$

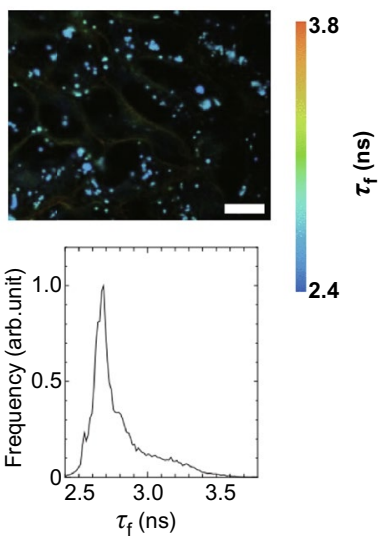

Fig. 6 FLIM combined with a specialized probe for intracellular environment change detection. a Left panel: Schematic representation of the response when QD-APBA (quantum dot-aminophenyl boronic acid) conjugates encounter glucose. Right panel: FLIM imaging of MDAMB-231 autofluorescence alone and under coexistence conditions, where MDA-MB-231 cells are incubated with 50 mM glucose and QD-APBA conjugates for $3 \mathrm{~h}$. The corresponding photoluminescence lifetime histogram is presented below. Reproduced with permission from Ref. [108]. Copyright 2019, MDPI; b Upper panel: Sensor principle of the peptide biosensor. Lower panel: HATS acetylation FLIM image in a 3D culture over 25 min after treatment with $5 \mu \mathrm{M}$ of anacardic acid (an inhibitor of PCAF acetylation activity), representing the capabilities of the peptide biosensor for acetylation level monitoring. Reproduced with permission from Ref. [106]. Copyright 2019, American Chemical Society; c FLIM images after HeLa cells are treated with oleic acid $(400 \mu \mathrm{M})$ for 0 and $24 \mathrm{~h}$. The cells were first co-cultured with PC6S $\left(2 \mu \mathrm{M}, 30 \mathrm{~min}, 37^{\circ} \mathrm{C}\right)$. The corresponding fluorescence lifetime distribution histograms are presented (excitation wavelength: $488 \mathrm{~nm}$, collected emission wavelength range: $510-560 \mathrm{~nm}$. scale bar: $20 \mu \mathrm{m}$.). Reproduced with permission from Ref. [109]. Copyright 2020, American Chemical Society

acid derivative coumarin), as well as drug distributions inside cells [131]. Generally, fluorescent drugs combined with FLIM are promising for drug delivery optimization, which can lead to better anti-cancer treatment outcomes.

\section{Conclusion and Outlook}

In general, according to its development history from autofluorescence molecules to fluorescent dyed probes and from intracellular substances to extracellular environments, FLIM has been widely applied to cancer diagnosis and treatment monitoring for further improvement. The applications of NAD(P)H-FLIM for metabolism, FRET-FLIM for molecular interaction, and fluorescent dyed probes aimed at specific aberrations all demonstrated FLIM's great potential for cancer research. With the development of new optical instruments and analysis methods, as well as cancer biomarker discoveries, the application of FLIM has broadened, and a rapid increase in FLIM-assisted clinical cancer diagnosis and tumor boundary determination cases have been reported. Additionally, as novel abnormities in cancer cells are uncovered, these discoveries can lead to anti-cancer drug innovations. Despite these inspiring achievements 
(a)

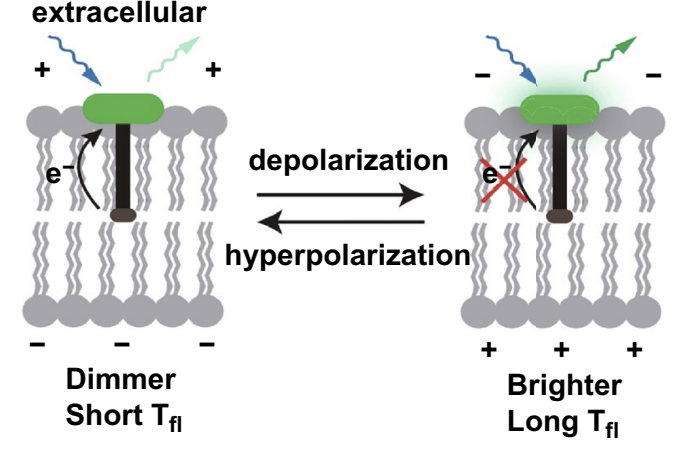

(b)

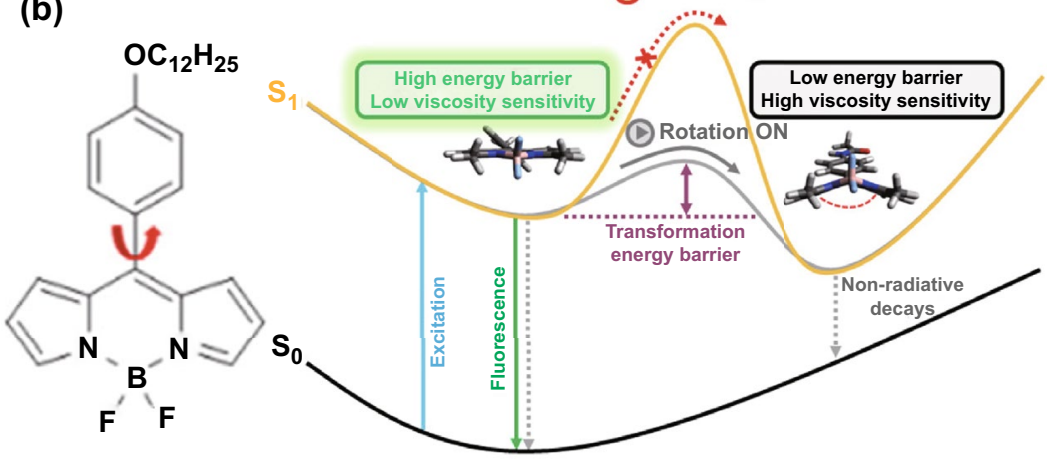

(c)
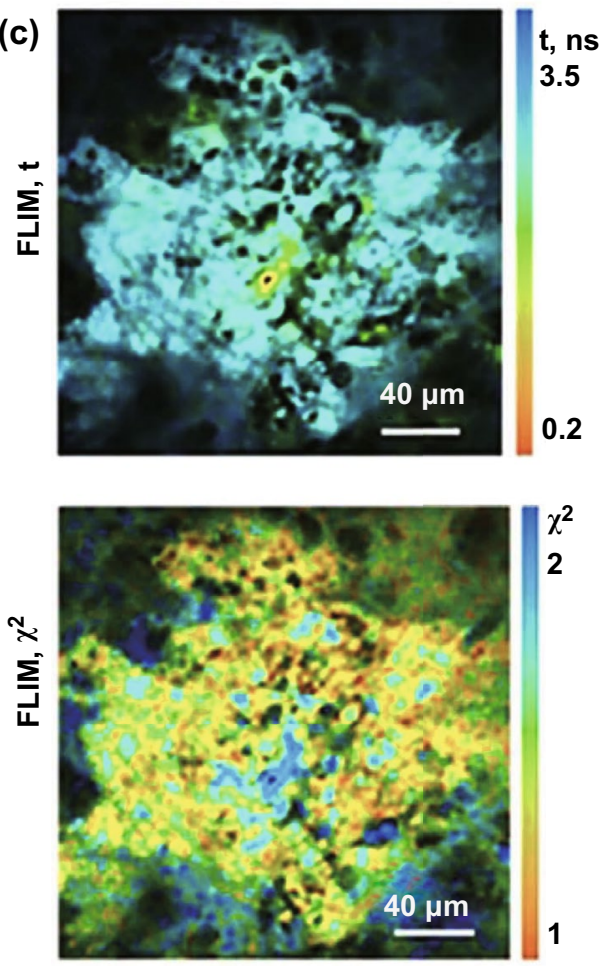

Fig. 7 FLIM application to membranes for cancer diagnosis and treatment based on altered membrane potential and viscosity. a Mechanism of VoltageFluor dyes in which depolarization of the membrane potential attenuates the rate of photoinduced electron transfer. Reproduced with permission from Ref. [110]. Copyright 2019, elife Sciences Publications. b Left panel: Representative BODIPY molecular rotor. Right panel: Simplified mechanism of BODIPY rotors. Reproduced with permission from Ref. [114]. Copyright 2020, American Chemical Society. c Representative in vivo FLIM images of a CT26 tumor at $60 \mathrm{~min}$ after an intravenous BODIPY2 $\left(3 \mathrm{mg} \mathrm{kg}^{-1}\right)$ injection. The excitation wavelength is $800 \mathrm{~nm}$ and the detection wavelength is $409-680 \mathrm{~nm}$. The upper FLIM image is used for lifetime/viscosity calibration and the lower image is a FLIM image of time-resolved fluorescence decay. Reproduced with permission from Ref. [117]. Copyright 2017, Springer Nature

so far, FLIM still has some shortcomings that must be addressed.

For realizing FLIM clinical application, there are numerous techniques for increasing imaging speed and resolution, which were discussed in detail in the introduction section. In particular, for faster FLIM, several commercial solutions are available for realizing imaging at kilohertz rates. For example, an apparatus from Becker \& Hickel can speed up imaging using an improved femtosecond laser and laser scanning vibration mirror, whereas the PicoQUant company has combined time-tagged and time-resolved data handling with a picosecond or femtosecond pulsed laser and singlephoton detector for faster imaging. In addition to improvements of FLIM itself, FLIM has also been increasingly integrated with a variety of optical techniques to gain a more comprehensive understanding of cancer cells based on novel nanospheres and optical systems [132, 133]. For example, for metastatic pancreatic cancer detection, a FLIM system containing a super-wide-tuning integrated multimodal platform for label-free evaluation has been constructed to collect detailed cell and milieu information [134].

Besides, as most bio-life researches are conducted in cell experiments or animal models, several issues are needed to be addressed from bench to bedside. Considering the potential toxicity of organic fluorophores or FPs, the biocompatibility and biodegradability of FRET pairs or fluorescent biosensors are primary problems that should be solved. Moreover, for in-vivo applications, the targeting ability to cancerous regions of biosensors for FLIM detection is vital for efficiency. Furthermore, most clinical in-vivo applications are restricted in skin, oral health, or tract surface because of the imaging depth limitation of traditional fluorophores. To solve this problem, near infrared (NIR) fluorophores, whose excitation and emission wavelengths are within $650-900 \mathrm{~nm}$, overcome the absorbance disadvantages, greatly elevating the penetration depth to centimeters 
(a)
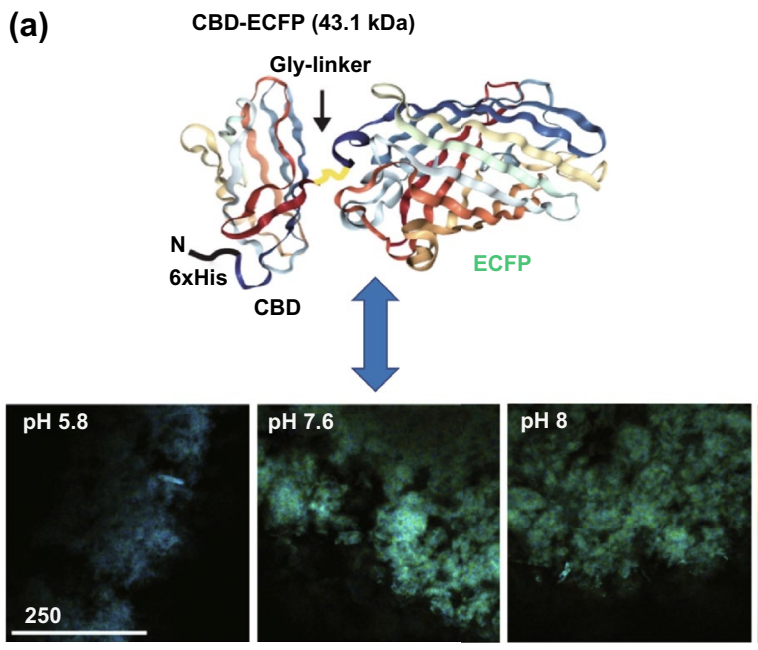

(b)
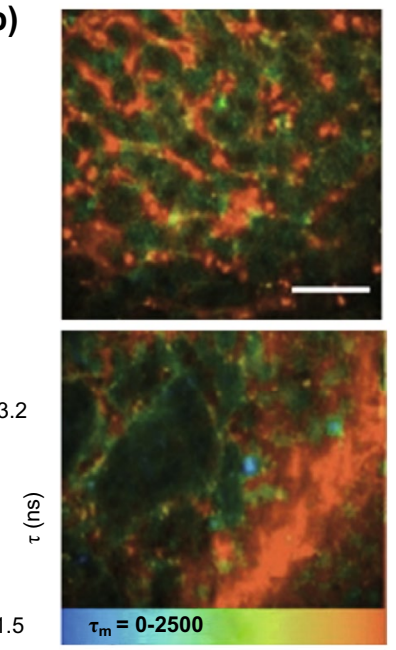
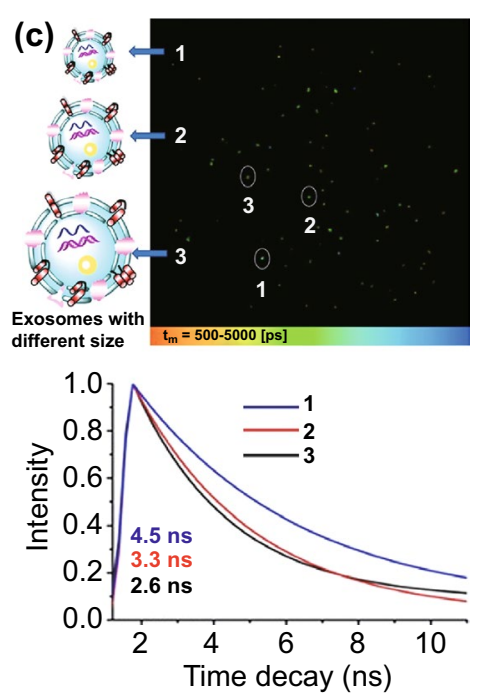

Fig. 8 FLIM application to extracellular environments. a Schematic representation of a CBD-ECFP biosensor. The upper panel shows the CBDECFP structure, where N-terminal 6xHis sequences are shown in black with CBD and ECFP domains linked by Gly-rich linker regions. The lower panel shows fluorescence lifetime images of a CBD-ECFP GrowDex matrix at different pH levels (scale bar is $1 \mu \mathrm{m}$ ). Reproduced with permission from Ref. [118]. Copyright 2018, Elsevier; b Pseudo-colored fluorescence lifetime image produced by multiphoton fluorescence lifetime imaging microscopy. The image shows healthy liver tissue above and hepatocellular carcinoma below following QD injection (recorded at $\lambda$ Exc/ $\lambda$ Em: 900/515 to $620 \mathrm{~nm}$; scale bar is $40 \mu \mathrm{m}$ ). Reproduced with permission from Ref. [119]. Copyright 2019, MDPI; c FLIM of exosomes of different sizes from tumor cells based on Mem-BDP probes. The upper and lower panels show FLIM images of exosomes of different sizes and their corresponding fluorescence decay curves, respectively. Reproduced with permission from Ref. [120]. Copyright 2019, American Chemical of Society

Table 4 Probe \& FLIM

\begin{tabular}{|c|c|c|c|c|}
\hline Aberration & Probe & Result & Potential application & Refs. \\
\hline Extra chromosome 12 & DNA binder: DAPI & FLT substantially increases & $\begin{array}{l}\text { Diagnosis and classification for } \\
\text { B-CLL and B-ALL }\end{array}$ & {$[103]$} \\
\hline Deletion of p53 & & FLT mildly increase & $\begin{array}{l}\text { Diagnosis and classification for } \\
\text { B-CLL and B-ALL }\end{array}$ & {$[103]$} \\
\hline G-quadruplex $\uparrow$ & NBTE & $\begin{array}{l}\text { G-quadruplex: cancer cells > nor- } \\
\text { mal cells }\end{array}$ & $\begin{array}{l}\text { Differentiating tumor cells from } \\
\text { healthy cells }\end{array}$ & {$[104]$} \\
\hline Acetylation on histone lysine & HATS & FLT $\uparrow$ & $\begin{array}{l}\text { Detecting acetyltransferase-PCAF } \\
\text { activity }\end{array}$ & {$[106]$} \\
\hline Cytoplasm environment change & ATTO425 labeled on AS1411 & FLT: tumor- $5.8 \mathrm{~ns}$ control- $4.3 \mathrm{~ns}$ & $\begin{array}{l}\text { Differentiating tumor cells from } \\
\text { healthy cells }\end{array}$ & {$[107]$} \\
\hline \multirow[t]{2}{*}{ Membrane potential change } & VoltageFluor dyes & Membrane potential $\uparrow \sim$ FLT $\uparrow$ & $\begin{array}{l}\text { Detecting membrane potential } \\
\text { change }\end{array}$ & {$[110]$} \\
\hline & SYTO/TMRM & $\begin{array}{l}\text { Mitochondria membrane poten- } \\
\text { tial } \uparrow \sim \text { FLT } \downarrow\end{array}$ & $\begin{array}{l}\text { Detecting mitochondria membrane } \\
\text { potential change }\end{array}$ & {$[111]$} \\
\hline \multirow[t]{3}{*}{ Membrane viscosity change } & BODIPY 2 & $\begin{array}{l}\text { Cisplatin treatment } \sim \text { viscos- } \\
\text { ity } \uparrow \sim \text { FLT } \uparrow\end{array}$ & $\begin{array}{l}\text { Monitoring of the tumor response } \\
\text { to anti-cancer therapy }\end{array}$ & {$[115]$} \\
\hline & BODIPYC10/BODIPY + + & $\begin{array}{l}\text { No viscosity difference in the } \\
\text { center and periphery of spheroids }\end{array}$ & $\begin{array}{l}\text { Non-invasive mapping of the vis- } \\
\text { cosity of living tumor spheroids }\end{array}$ & {$[116]$} \\
\hline & BODIPY 1/BODIPY 2 & $\begin{array}{l}\text { Viscosity imaging in CT26 subcu- } \\
\text { taneous tumors in vivo } \sqrt{ }\end{array}$ & $\begin{array}{l}\text { In vivo monitoring of viscosity of } \\
\text { tumor }\end{array}$ & {$[117]$} \\
\hline $\mathrm{pH}$ change & CBD-ECFP & $\mathrm{pH} \uparrow \sim \mathrm{FLT} \uparrow$ & $\begin{array}{l}\text { Detecting } \mathrm{pH} \text { in the tumor micro- } \\
\text { environment }\end{array}$ & {$[118]$} \\
\hline Vascular disorder & QDs & Tortuous vascular in tumor tissue & Imaging of vascular based on QDs & {$[119]$} \\
\hline
\end{tabular}


(a)

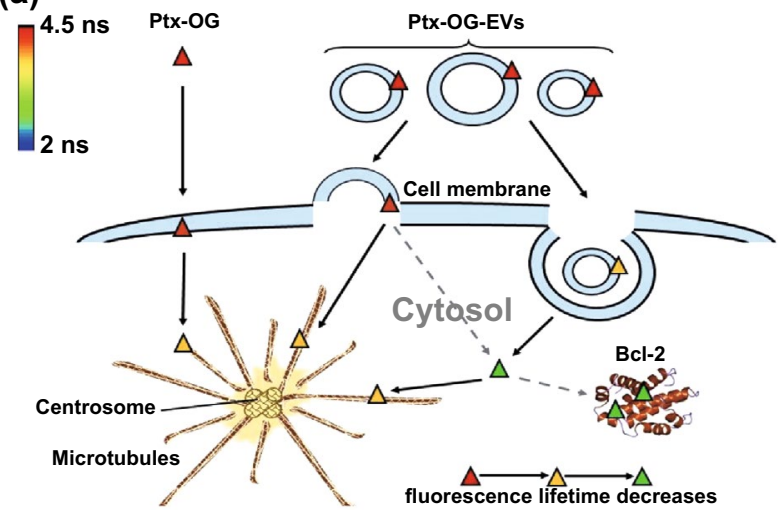

(c)

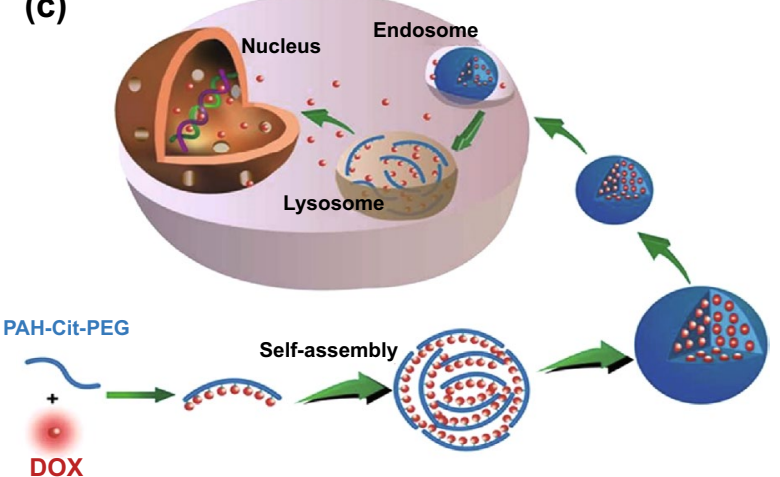

(b)

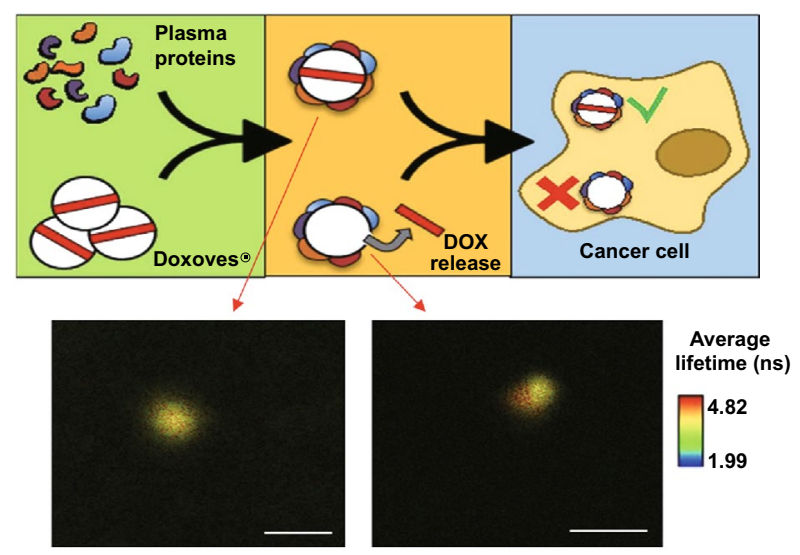

(d)

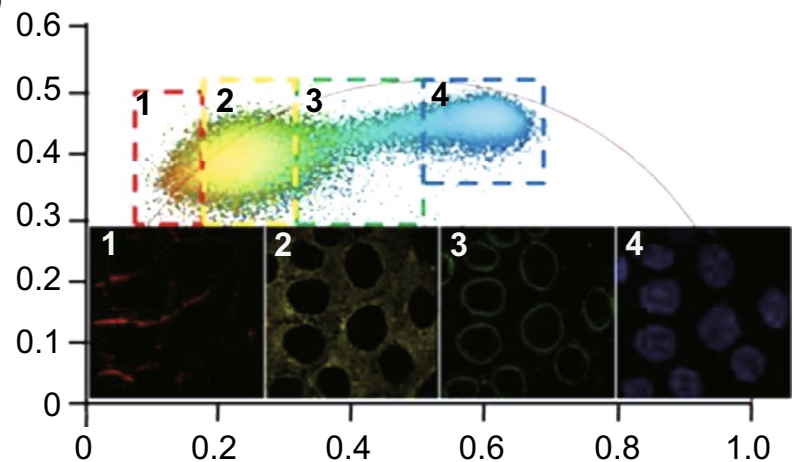

Fig. 9 Fluorescent anti-cancer drug in combination with FLIM for drug delivery and treatment improvement. a Drug entry pathway: Scheme of OG fluorophore-dyed Ptx and EV-mediated Ptx-OG cell entry pathways. Different sizes of vesicles represent the EV size heterogeneity considered in this study. The colors of Ptx-OG in the figure (red, yellow, green) are consistent with the FLIM image color scale. Solid arrows represent guaranteed pathways of Ptx-OG and Ptx-OG-Evs into the cell, while dashed arrows represent presumed pathways required for proving effectiveness. Reproduced with permission from Ref. [123]. Copyright 2018, Elsevier. b Drug delivery outside a cell: scheme of the dynamic BC formation of liposome DOX, determining the success or failure of liposomal drugs. Reproduced with permission from Ref. [124]. Copyright 2018, American Chemical of Society. c Scheme of a DOX-loaded nanostructure and drug release in a cell triggered by a lower $\mathrm{pH}$. Dox was covalently loaded onto a $\mathrm{pH}$-sensitive polymer (poly(allylamine)citraconic anhydride, $\mathrm{PAH}-\mathrm{Cit}$ ) for the $\mathrm{pH}$-sensitive release of Dox. The entire process was monitored by Phasor-FLIM. Reproduced with permission from Ref. [129]. Copyright 2018, American Chemical Society. d Intracellular drug distribution: Phasor-FLIM of MCF-7 cells incubated with PAH-Cit/DOX after $6 \mathrm{~h}$. Phasor plot of FLIM images shown above. Reproduced with permission from Ref. [129]. Copyright 2018, American Chemical Society. (Color figure online)

[135]. These NIR fluorophores greatly broaden the application fields, which especially deserve medical investigator's attention.

To further broaden the application region of FLIM, FLIM in combination with $\mathrm{NAD}(\mathrm{P}) \mathrm{H}$ for metabolism change detection can be adopted not only in cancer cells, but also in adjacent cells, such as immune cells for improving immunotherapy and neuron cells for deepening our understanding of cancer neuroscience studies [136, 137]. Additionally, extracellular vesicles (EVs) based method can combine with FLIM to play a significant role in both diagnosis and treatment monitoring. FLIM is hopeful for specific exRNA detection based on novel RNA probes targeting specific
RNA sequences. As shown in Fig. 10, if a probe binds to a particular RNA sequence, the corresponding fluorescence lifetime can be analyzed by a computer. As high-throughput sequencing continues to develop, optimized FLIM probe arrays should enable the rapid and sensitive exRNA detection of oncosomes, which could surpass traditional sequencing techniques. Regarding anti-cancer treatment, by using EVs to deliver RNAs, such as long noncoding RNAs and circular RNAs, to proximal and distant recipient cells to avoid the RNAase effect, exRNA-loaded EVs can achieve better treatment outcomes [138, 139]. Considering the stable presence of extracellular RNAs (exRNAs) in EVs, EVs can load transfected specific RNA such as siRNA, miRNA, and 


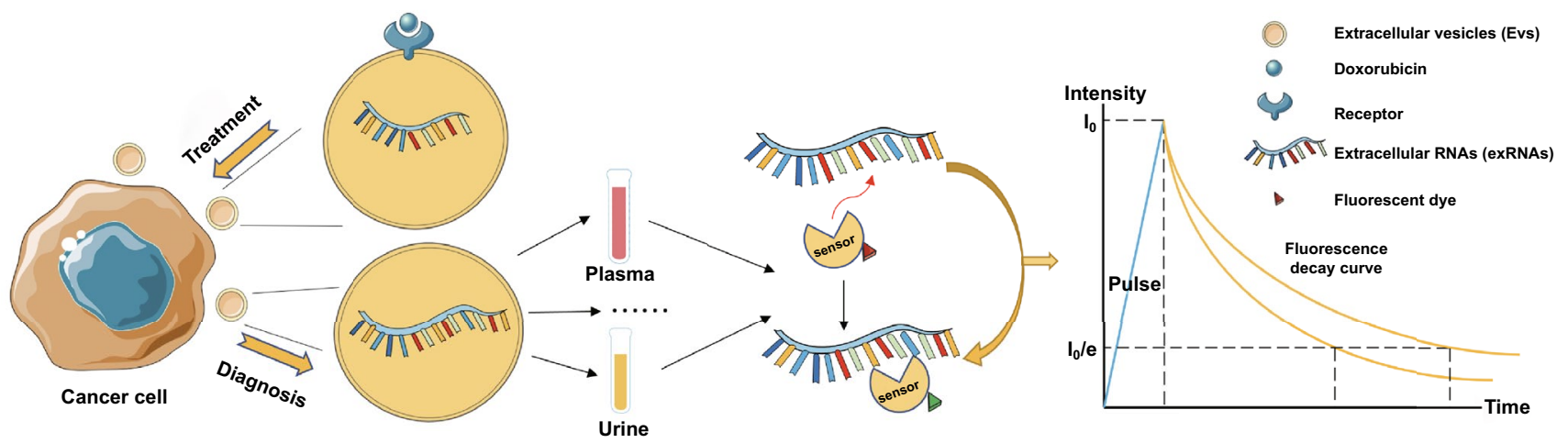

Fig. 10 Scheme of exosome based FLIM potential application for cancer diagnosis and treatment monitoring. This novel treatment strategy is based on the co-delivery of fluorescent anti-cancer drugs such as doxorubicin with exRNAs. The cancer diagnosis strategy is based on the targeted exRNA detection of oncosomes. In this diagnosis method, fluorescent-dyed biosensors identify the specific base sequences of exRNAs in body fluids, which will exhibit fluorescence lifetime changes that can be detected by FLIM

fluorescence anti-cancer drugs based on FLIM monitoring. Such EVs are promising for improved anti-cancer targeted therapy and the entire delivery process can be precisely tracked by FLIM. Although extracellular vesicle-mediated RNA delivery has been demonstrated previously, combining fluorescent drugs and exRNA with FLIM for cancer therapeutic effect improvement has recently been proposed for the first time [140]. Collectively, the researches up to now have demonstrated the potential of FLIM as a promising tool for cancer diagnosis and treatment monitoring, and future studies, including FLIM optimization and fluorophore improvement, are warranted for its efficacy improvement on clinical applications.

Acknowledgements This work was partially supported by the National Natural Science Foundation of China (Grant No. 61775241), the Hunan Science Fund for Distinguished Young Scholar (2020JJ2059), Youth Innovation Team (Grant No. 2019012) of CSU, Hunan province key research and development project (Grant No. 2019GK2233, Grant 2020SK2053), Hunan Province Graduate Research and Innovation Project (Grant No. CX20190177), the Science and Technology Innovation Basic Research Project of Shenzhen(Grant No. JCYJ20180307151237242). Also, YPL acknowledges the support by the Project of State Key Laboratory of High-Performance Complex Manufacturing, Central South University (Grant No. ZZYJKT2020-12). Besides, we acknowledge the art work from Servier Medical Art. Y.Z.O and Y.P.L contributed equally to this work.

Open Access This article is licensed under a Creative Commons Attribution 4.0 International License, which permits use, sharing, adaptation, distribution and reproduction in any medium or format, as long as you give appropriate credit to the original author(s) and the source, provide a link to the Creative Commons licence, and indicate if changes were made. The images or other third party material in this article are included in the article's Creative Commons licence, unless indicated otherwise in a credit line to the material. If material is not included in the article's Creative Commons licence and your intended use is not permitted by statutory regulation or exceeds the permitted use, you will need to obtain permission directly from the copyright holder. To view a copy of this licence, visit http://creativecommons.org/licenses/by/4.0/.

\section{References}

1. M. Chalfie, Y. Tu, G. Euskirchen, W.W. Ward, D.C. Prasher, Green fluorescent protein as a marker for gene expression. Science 263(5148), 802-805 (1994). https://doi.org/10.1126/ science. 8303295

2. W. Becker, Fluorescence lifetime imaging-techniques and applications. J. Microsc. 247(2), 119-136 (2012). https:// doi.org/10.1111/j.1365-2818.2012.03618.x

3. X.B. Liu, D.Y. Lin, Q.Q. Wu, Y. Wei, T. Luo et al., Recent progress of fluorescence lifetime imaging microscopy technology and its application. Acta Phys. Sin. 67(17), 14 (2018). https://doi.org/10.7498/aps.67.20180320

4. A.J. Walsh, J.T. Sharick, M.C. Skala, H.T. Beier, Temporal binning of time-correlated single photon counting data improves exponential decay fits and imaging speed. Biomed. Opt. Express 7(4), 1385-1399 (2016). https://doi.org/10. 1364/boe.7.001385

5. X.B. Liu, D.Y. Lin, W. Becker, J.J. Niu, B. Yu et al., Fast fluorescence lifetime imaging techniques: a review on challenge and development. J. Innov. Opt. Health Sci. 12(5), 27 (2019). https://doi.org/10.1142/s1793545819300039

6. W. Hu, L. Guo, L. Bai, X. Miao, Y. Ni et al., Maximizing aggregation of organic fluorophores to prolong fluorescence lifetime for two-photon fluorescence lifetime imaging. Adv. 
Healthc. Mater. (2018). https://doi.org/10.1002/adhm.20180 0299

7. T. He, C. Ren, Z. Li, S. Xiao, J. Li et al., Thermally activated delayed fluorescence organic dots for two-photon fluorescence lifetime imaging. Appl. Phys. Lett. 112(21), 4 (2018). https://doi.org/10.1063/1.5034375

8. H. Ranawat, S. Pal, N. Mazumder, Recent trends in twophoton auto-fluorescence lifetime imaging (2P-FLIM) and its biomedical applications. Biomed. Eng. Lett. 9(3), 293-310 (2019). https://doi.org/10.1007/s13534-019-00119-7

9. H. Li, J. Yu, R. Zhang, X. Li, W. Zheng, Two-photon excitation fluorescence lifetime imaging microscopy: a promising diagnostic tool for digestive tract tumors. J. Innov. Opt. Health Sci. 12(5), 16 (2019). https://doi.org/10.1142/s1793 54581930009x

10. K. König, A. Ehlers, I. Riemann, S. Schenkl, R. Bückle et al., Clinical two-photon microendoscopy. Microsc. Res. Tech. 70(5), 398-402 (2007). https://doi.org/10.1002/jemt.20445

11. K. König, Review: clinical in vivo multiphoton flim tomography. Methods Appl. Fluoresc. (2020). https://doi.org/10. 1088/2050-6120/ab8808

12. Y. Sun, A. Periasamy, in Localizing protein-protein interactions in living cells using fluorescence lifetime imaging microscopy. ed. by VERVEER P J (Humana Press Inc, 999 Riverview Dr, Ste 208, Totowa, Nj 07512-1165 USA; 2015), pp. $83-107$

13. B. Sauer, Q. Tian, P. Lipp, L. Kaestner, Confocal FLIM of genetically encoded FRET sensors for quantitative $\mathrm{Ca}^{2+}$ imaging. Cold Spring Harb. Protoc. 2014(12), 1328-1332 (2014). https://doi.org/10.1101/pdb.prot077040

14. F. Festy, S.M. Ameer-Beg, T. Ng, K. Suhling, Imaging proteins in vivo using fluorescence lifetime microscopy. Mol. Biosyst. 3(6), 381-391 (2007). https://doi.org/10.1039/b6172 $04 \mathrm{k}$

15. Z. Shi, X. Han, W. Hu, H. Bai, B. Peng et al., Bioapplications of small molecule aza-bodipy: from rational structural design to in vivo investigations. Chem. Soc. Rev. 49(21), 7533-7567 (2020). https://doi.org/10.1039/d0cs00234h

16. L.M. Hirvonen, K. Suhling, Fast timing techniques in FLIM applications. Front. Phys. 8, 20 (2020). https://doi.org/10. 3389/fphy.2020.00161

17. S. Rajoria, L. Zhao, X. Intes, M. Barroso, FLIM-FRET for cancer applications. Curr. Mol. Imaging 3(2), 144-161 (2014). https://doi.org/10.2174/22115552036661411172 21111

18. L.C. Chen, W.R. Lloyd, C.W. Chang, D. Sud, M.A. Mycek, in Fluorescence Lifetime Imaging Microscopy for Quantitative Biological Imaging. ed.by SLUDER G, WOLF D E (Elsevier Academic Press Inc; San Diego, 2013), pp. 457-488

19. W. Becker, A. Bergmann, M.A. Hink, K. Konig, K. Benndorf et al., Fluorescence lifetime imaging by time-correlated single-photon counting. Microsc. Res. Tech. 63(1), 58-66 (2004). https://doi.org/10.1002/jemt.10421

20. J. Requejo-Isidro, J. McGinty, I. Munro, D.S. Elson, N.P. Galletly et al., High-speed wide-field time-gated endoscopic fluorescence-lifetime imaging. Opt. Lett. 29(19), 2249-2251 (2004). https://doi.org/10.1364/ol.29.002249

21. R.V. Krishnan, H. Saitoh, H. Terada, V.E. Centonze, B. Herman, Development of a multiphoton fluorescence lifetime imaging microscopy system using a streak camera. Rev. Sci. Instrum. 74(5), 2714-2721 (2003). https://doi.org/10.1063/1. 1569410

22. L. Martelo, A. Fedorov, M.N. Berberan-Santos, Fluorescence phasor plots using time domain data: effect of the instrument response function. J. Phys. Chem. B 119(32), 10267-10274 (2015). https://doi.org/10.1021/acs.jpcb.5b00261

23. A. Vallmitjana, A. Dvornikov, B. Torrado, D.M. Jameson, S. Ranjit et al., Resolution of 4 components in the same pixel in FLIM images using the phasor approach. Methods Appl. Fluoresc. 8(3), 9 (2020). https://doi.org/10.1088/2050-6120/ ab8570

24. N. Ma, M.A. Digman, L. Malacrida, E. Gratton et al., Measurements of absolute concentrations of NADH in cells using the phasor FLIM method. Bio. Opt. Express 7(7), 2441-2452 (2016). https://doi.org/10.1364/boe.7.002441

25. T.S. Blacker, M.R. Duchen, Investigating mitochondrial redox state using NADH and NADPH autofluorescence. Free Radic. Biol. Med. 100, 53-65 (2016). https://doi.org/10.1016/j.freer adbiomed.2016.08.010

26. G. Einstein, K. Udayakumar, D. Koteeswaran, P. Aruna, S. Ganesan et al., Polarization gating technique extracts depth resolved fluorescence redox ratio in oral cancer diagnostics. Photodiagn. Photodyn. Ther. 8, 30 (2020). https://doi.org/10. 1016/j.pdpdt.2020.101757

27. Y. Jing, Y. Wang, X. Wang, C. Song, J. Ma et al., Labelfree imaging and spectroscopy for early detection of cervical cancer. J. Biophotonics (2018). https://doi.org/10.1002/jbio. 201700245

28. R. Niesner, B. Peker, P. Schlusche, K.H. Gericke, Noniterative biexponential fluorescence lifetime imaging in the investigation of cellular metabolism by means of NAD $(\mathrm{P}) \mathrm{H}$ autofluorescence. ChemPhysChem 5(8), 1141-1149 (2004). https://doi.org/10.1002/cphc.200400066

29. T.S. Blacker, R.J. Marsh, M.R. Duchen, A.J. Bain, Activated barrier crossing dynamics in the non-radiative decay of NADH and NADPH. Chem. Phys. 422, 184-194 (2013). https://doi.org/10.1016/j.chemphys.2013.02.019

30. O. Warburg, On the origin of cancer cells. Science 123(3191), 309-314 (1956). https://doi.org/10.1126/science.123.3191. 309

31. M. Wang, F. Tang, X. Pan, L. Yao, X. Wang et al., Rapid diagnosis and intraoperative margin assessment of human lung cancer with fluorescence lifetime imaging microscopy. BBA Clin. 8, 7-13 (2017). https://doi.org/10.1016/j.bbacli. 2017.04.002

32. K. Awasthi, D. Moriya, T. Nakabayashi, L. Li, N. Ohta, Sensitive detection of intracellular environment of normal and cancer cells by autofluorescence lifetime imaging. J. Photochem. Photobiol. B 165, 256-265 (2016). https://doi.org/10. 1016/j.jphotobiol.2016.10.023 
33. M. Brandao, R. Iwakura, F. Basilio, K. Haleplian, A. Ito et al., Fluorescence lifetime of normal, benign, and malignant thyroid tissues. J. Biomed. Opt. (2015). https://doi.org/ 10.1117/1.Jbo.20.6.067003

34. M.G. Vander Heiden, L.C. Cantley, C.B. Thompson, Understanding the warburg effect: the metabolic requirements of cell proliferation. Science 324(5930), 1029-1033 (2009). https://doi.org/10.1126/science.1160809

35. T.M. Ashton, W.G. McKenna, L.A. Kunz-Schughart, G.S. Higgins, Oxidative phosphorylation as an emerging target in cancer therapy. Clin. Cancer Res. 24(11), 2482-2490 (2018). https://doi.org/10.1158/1078-0432.Ccr-17-3070

36. A. Schroeder, K. Pointer, P. Clark, R. Datta, J. Kuo et al., Metabolic mapping of glioblastoma stem cells reveals NADH fluxes associated with glioblastoma phenotype and survival. J. Biomed. Opt. 25(3), 1-13 (2020). https://doi.org/10. 1117/1.Jbo.25.3.036502

37. S. Gershanov, S. Michowiz, H. Toledano, G. Yahav, O. Barinfeld et al., Fluorescence lifetime imagingmicroscopy, a novel diagnostic tool for metastatic cell detection in the cerebrospinal fluid of children with medulloblastoma. Sci. Rep. 7(1), 3648 (2017). https://doi.org/10.1038/s41598-017-03892-6

38. J.M. Funes, M. Quintero, S. Henderson, D. Martinez, U. Qureshi et al.,Transformation of human mesenchymal stem cells increases their dependency on oxidative phosphorylation for energy production. Proc. Natl. Acad. Sci. USA 104(15), 6223-6228 (2007). https://doi.org/10.1073/pnas. 0700690104

39. C. Jose, N. Bellance, R. Rossignol, Choosing between glycolysis and oxidative phosphorylation: a tumor's dilemma? Biochim. Biophys. Acta 1807(6), 552-561 (2011). https:// doi.org/10.1016/j.bbabio.2010.10.012

40. V.S. LeBleu, J.T. O'Connell, K.N. Gonzalez Herrera, H. Wikman, K. Pantel et al., Pgc-1 $\alpha$ mediates mitochondrial biogenesis and oxidative phosphorylation in cancer cells to promote metastasis. Nat. Cell Biol. 16(10), 992-1003 (2014). https://doi.org/10.1038/ncb3039

41. H. Wu, M.F. Ying, X. Hu et al., Lactic acidosis switches cancer cells from aerobic glycolysis back to dominant oxidative phosphorylation. Oncotarget 7(26), 40621-40629 (2016). https://doi.org/10.18632/oncotarget.9746

42. A.J. Bower, J.E. Sorrells, J. Li, M. Marjanovic, R. Barkalifa et al., Tracking metabolic dynamics of apoptosis with highspeed two-photon fluorescence lifetime imaging microscopy. Biomed. Opt. Express. 10(12), 6408-6421 (2019). https://doi. org/10.1364/boe. 10.006408

43. A.J. Bower, J. Li, E.J. Chaney, M. Marjanovic, D.R. Spillman et al., High-speed imaging of transient metabolic dynamics using two-photon fluorescence lifetime imaging microscopy. Optica 5(10), 1290-1296 (2018). https://doi.org/10.1364/ optica.5.001290

44. M.M. Lukina, L.E. Shimolina, N.M. Kiselev, V.E. Zagainov, D.V. Komarov et al., Interrogation of tumor metabolism in tissue samples ex vivo using fluorescence lifetime imaging of NAD(P)H. Methods Appl. Fluoresc. 8(1), 11 (2020). https:// doi.org/10.1088/2050-6120/ab4ed8
45. T. Zahavi, G. Yahav, Y. Shimshon, S. Gershanov, L. Kaduri et al., Utilizing fluorescent life time imaging microscopy technology for identify carriers of BRCA2 mutation. Biochem. Biophys. Res. Commun. 480(1), 36-41 (2016). https:// doi.org/10.1016/j.bbrc.2016.10.013

46. M.J. Huang, Z.X. Zhang, X.Y. Wang, Y.H. Xie, Y.Y. Fei et al., Detecting benign uterine tumors by autofluorescence lifetime imaging microscopy through adjacent healthy cervical tissues. J. Innov. Opt. Health Sci. 12(5), 11 (2019). https:// doi.org/10.1142/s1793545819400066

47. M. Lee, J.-H. Yoon, Metabolic interplay between glycolysis and mitochondrial oxidation: the reverse warburg effect and its therapeutic implication. World J. Biol. Chem. 6(3), 148-161 (2015). https://doi.org/10.4331/wjbc.v6.i3.148

48. J.M. Buschhaus, B.A. Humphries, S.S. Eckley, T.H. Robison, A.C. Cutter et al., Targeting disseminated estrogenreceptor-positive breast cancer cells in bone marrow. Oncogene 39(34), 5649-5662 (2020). https://doi.org/10.1038/ s41388-020-01391-z

49. I.N. Druzhkova, M.V. Shirmanova, M.M. Lukina, V.V. Dudenkova, N.M. Mishina et al., The metabolic interaction of cancer cells and fibroblasts-coupling between NAD $(\mathrm{P}) \mathrm{H}$ and $\mathrm{FAD}$, intracellular $\mathrm{pH}$ and hydrogen peroxide. Cell Cycle 15(9), 1257-1266 (2016). https://doi.org/10.1080/15384101. 2016.1160974

50. B.L. Cox, S. Erickson-Bhatt, J.M. Szulczewski, J.M. Squirrell, K.D. Ludwig et al., A novel bioreactor for combined magnetic resonance spectroscopy and optical imaging of metabolism in 3d cell cultures. Magn. Reson. Med. 81(5), 3379-3391 (2019). https://doi.org/10.1002/mrm.27644

51. J.T. Sharick, P.F. Favreau, A.A. Gillette, S.M. Sdao, M.J. Merrins et al., Protein-bound NAD(P)H lifetime is sensitive to multiple fates of glucose carbon. Sci. Rep. 8(1), 5456 (2018). https://doi.org/10.1038/s41598-018-23691-X

52. D.K. Bird, L. Yan, K.M. Vrotsos, K.W. Eliceiri, E.M. Vaughan et al., Metabolic mapping of MCF10a human breast cells via multiphoton fluorescence lifetime imaging of the coenzyme nadh. Cancer Res. 65(19), 8766-8773 (2005). https://doi.org/10.1158/0008-5472.Can-04-3922

53. D. Morone, F.D. Autilia, T. Schorn, M. Erreni, A. Doni, Evaluation of cell metabolic adaptation in wound and tumour by fluorescence lifetime imaging microscopy. Sci. Rep. 10(1), 6289 (2020). https://doi.org/10.1038/s41598-020-63203-4

54. M.N. Pastore, H. Studier, C.S. Bonder, M.S. Roberts, Noninvasive metabolic imaging of melanoma progression. Exp. Dermatol. 26(7), 607-614 (2017). https://doi.org/10.1111/ exd.13274

55. K.T. Pate, C. Stringari, S. Sprowl-Tanio, K. Wang, T. TeSlaa et al., Wnt signaling directs a metabolic program of glycolysis and angiogenesis in colon cancer. EMBO J 33(13), 1454-1473 (2014). https://doi.org/10.15252/embj.201488598

56. X. Wang, Y. Wang, Z. Zhang, M. Huang, Y. Fei et al., Discriminating different grades of cervical intraepithelial neoplasia based on label-free phasor fluorescence lifetime imaging microscopy. Biomed. Opt. Express 11(4), 1977-1990 (2020). https://doi.org/10.1364/boe.386999 
57. A.L. Trinh, H. Chen, Y. Chen, Y. Hu, Z. Li et al., Tracking functional tumor cell subpopulations of malignant glioma by phasor fluorescence lifetime imaging microscopy of NADH. Cancers 9(12), 13 (2017). https://doi.org/10.3390/cancers912 0168

58. D.H. Lee, X. Li, N. Ma, M.A. Digman, A.P. Lee, Rapid and label-free identification of single leukemia cells from blood in a high-density microfluidic trapping array by fluorescence lifetime imaging microscopy. Lab Chip 18(9), 1349-1358 (2018). https://doi.org/10.1039/c7lc01301a

59. T. Luo, Y. Lu, S. Liu, D. Lin, J. Qu, Phasor-FLIM as a screening tool for the differential diagnosis of actinic keratosis, bowen's disease, and basal cell carcinoma. Anal. Chem. 89(15), 8104-8111 (2017). https://doi.org/10.1021/acs.analc hem.7b01681

60. A.C.B. Sant'Anna-Silva, G.C. Santos, S.P.C. Campos, A.M. Oliveira Gomes, J.A. Pérez-Valencia et al., Metabolic profile of oral squamous carcinoma cell lines relies on a higher demand of lipid metabolism in metastatic cells. Front. Oncol. 8, 13 (2018). https://doi.org/10.3389/fonc.2018.00013

61. L. Kong, M.M. Murata, M.A. Digman, Absence of REV3L promotes p53-regulated cancer cell metabolism in cisplatintreated lung carcinoma cells. Biochem. Biophys. Res. Commun. 496(1), 199-204 (2018). https://doi.org/10.1016/j.bbrc. 2018.01 .026

62. H. Wallrabe, Z. Svindrych, S.R. Alam, K.H. Siller, T. Wang et al., Segmented cell analyses to measure redox states of autofluorescent NAD(P)H, FAD \& Trp in cancer cells by flim. Sci. Rep. 8(1), 79 (2018). https://doi.org/10.1038/ s41598-017-18634-x

63. S.R. Alam, H. Wallrabe, Z. Svindrych, A.K. Chaudhary, K.G. Christopher et al., Investigation of mitochondrial metabolic response to doxorubicin in prostate cancer cells: an NADH, FAD and Tryptophan FLIM assay. Sci. Rep. 7(1), 10451 (2017). https://doi.org/10.1038/s41598-017-10856-3

64. S. Cheng, R.M. Cuenca, B. Liu, B.H. Malik, J.M. Jabbour et al., Handheld multispectral fluorescence lifetime imaging system for in vivo applications. Biom. Opt. Express 5(3), 921-931 (2014). https://doi.org/10.1364/BOE.5.000921

65. B.H. Malik, J. Lee, S. Cheng, R. Cuenca, J.M. Jabbour et al., Objective detection of oral carcinoma with multispectral fluorescence lifetime imaging in vivo. Photochem. Photobiol. 92(5), 694-701 (2016). https://doi.org/10.1111/php.12627

66. E. Duran-Sierra, S. Cheng, R. Cuenca-Martinez, B. Malik, K.C. Maitland et al., Clinical label-free biochemical and metabolic fluorescence lifetime endoscopic imaging of precancerous and cancerous oral lesions. Oral. Oncol. (2020). https://doi.org/10.1016/j.oraloncology.2020.104635

67. J.A. Jo, S. Cheng, R. Cuenca-Martinez, E. Duran-Sierra, B. Malik et al., Endogenous fluorescence lifetime imaging (FLIM) endoscopy for early detection of oral cancer and dysplasia. Annu. Int. Conf. IEEE Eng. Med. Biol. Soc. 1, 3009-3012 (2018). https://doi.org/10.1109/embc.2018.85130 27

68. R.A. Romano, R.G.T. Rosa, A.G. Salvio, J.A. Jo, C. Kurachi, Multispectral autofluorescence dermoscope for skin lesion assessment. Photodiagn. Photodyn. Therapy (2020). https:// doi.org/10.1016/j.pdpdt.2020.101704

69. F. Poulon, J. Pallud, P. Varlet, M. Zanello, F. Chretien et al., Real-time brain tumor imaging with endogenous fluorophores: a diagnosis proof-of-concept study on fresh human samples. Sci Rep 8, 14888 (2018). https://doi.org/10.1038/ s41598-018-33134-2

70. J.E. Phipps, D. Gorpas, J. Unger, M. Darrow, R.J. Bold et al., Automated detection of breast cancer in resected specimens with fluorescence lifetime imaging. Phys. Med. Biol. (2017). https://doi.org/10.1088/1361-6560/aa983a

71. B. Chen, Y. Lu, W. Pan, J. Xiong, Z. Yang et al., Support vector machine classification of nonmelanoma skin lesions based on fluorescence lifetime imaging microscopy. Anal. Chem. 91(16), 10640-10647 (2019). https://doi.org/10.1021/ acs.analchem.9b01866

72. S. Wang, F. Ji, Z. Li, M. Xue, Fluorescence imaging-based methods for single-cell protein analysis. Anal. Bioanal. Chem. 411(19), 4339-4347 (2019). https://doi.org/10.1007/ s00216-019-01694-5

73. R. Penjweini, B. Roarke, G. Alspaugh, A. Gevorgyan, A. Andreoni et al., Single cell-based fluorescence lifetime imaging of intracellular oxygenation and metabolism. Redox Biol. (2020). https://doi.org/10.1016/j.redox.2020.101549

74. H. Wallrabe, A. Periasamy, Imaging protein molecules using FRET and FLIM microscopy. CurrOpin Biotechnol. 16(1), 19-27 (2005). https://doi.org/10.1016/j.copbio.2004.12.002

75. N. Manjubaashini, M.P. Kesavan, J. Rajesh, T. Daniel Thangadurai, Multispectroscopic and bioimaging approach for the interaction of rhodamine $6 \mathrm{~g}$ capped gold nanoparticles with bovineserum albumin. J. Photochem. Photobiol. B 183, 374-384 (2018). https://doi.org/10.1016/j.jphotobiol.2018. 05.005

76. K.J. Martin, E.J. McGhee, J.P. Schwarz, M. Drysdale, S.M. Brachmann et al., Accepting from the best donor; analysis of long-lifetime donor fluorescent protein pairings to optimise dynamic flim-based fret experiments. PLoS ONE (2018). https://doi.org/10.1371/journal.pone.0183585

77. A. Xiao, A.E. Gibbons, K.E. Luker, G.D. Luker, Fluorescence lifetime imaging of apoptosis. Tomography 1(2), 115-124 (2015). https://doi.org/10.18383/j.tom.2015.00163

78. J.M. Buschhaus, B. Humphries, K.E. Luker, G.D. Luker, A caspase-3 reporter for fluorescence lifetime imaging of single-cell apoptosis. Cells 7(6), 57 (2018). https://doi.org/10. 3390/cells7060057

79. M. Pajic, D. Herrmann, C. Vennin, J.R. Conway, V.T. Chin et al., The dynamics of Rho GTPase signaling and implications for targeting cancer and the tumor microenvironment. Small GTPases 6(2), 123-133 (2015). https://doi.org/10. 4161/21541248.2014.973749

80. M. Nobis, D. Herrmann, S.C. Warren, S. Kadir, W. Leung et al., A RhoA-FRET biosensor mouse for intravital imaging in normal tissue homeostasis and disease contexts. Cell Rep. 21(1), 274-288 (2017). https://doi.org/10.1016/j.celrep.2017. 09.022 
81. F. Sizaire, G. Le Marchand, J. Pécréaux, O. Bouchareb, M. Tramier, Automated screening of AURKA activity based on a genetically encoded FRET biosensor using fluorescence lifetime imaging microscopy. Methods Appl. Fluoresc. (2020). https://doi.org/10.1088/2050-6120/ab73f5

82. G. Chennell, R.J. Willows, S.C. Warren, D. Carling, P.M. French et al., Imaging of metabolic status in $3 \mathrm{~d}$ cultures with an improved AMPK FRET biosensor for FLIM. Sensors 16(8), 1312 (2016). https://doi.org/10.3390/s16081312

83. J. Miles, C.J. Applebee, P. Leboucher, S. Lopez-Fernandez, D.J. Lee et al., Time resolved amplified FRET identifies protein kinase $b$ activation state as a marker for poor prognosis in clear cell renal cell carcinoma. BBA Clin. 8, 97-102 (2017). https://doi.org/10.1016/j.bbacli.2017.10.002

84. M. Lu, L.W. Tay, J. He, G. Du, Monitoring phosphatidic acid signaling in breast cancer cells using genetically encoded biosensors. Methods Mol. Biol. 1406, 225-237 (2016). https:// doi.org/10.1007/978-1-4939-3444-7_20

85. A. Buntz, S. Wallrodt, E. Gwosch, M. Schmalz, S. Beneke et al., Real-time cellular imaging of protein poly(ADP-ribos) ylation. Angew. Chem. Int. Ed. 55(37), 11256-11260 (2016). https://doi.org/10.1002/anie.201605282

86. J.R.W. Conway, S.C. Warren, P. Timpson, Context-dependent intravital imaging of therapeutic response using intramolecular FRET biosensors. Methods 128, 78-94 (2017). https://doi. org/10.1016/j.ymeth.2017.04.014

87. A. Losada, M.J. Muñoz-Alonso, C. García, P.A. SánchezMurcia, J.F. Martínez-Leal et al., Translation elongation factor eEF1A2 is a novel anticancer target for the marine natural product plitidepsin. Sci. Rep. 6, 35100 (2016). https://doi.org/ 10.1038/srep35100

88. W. Ashraf, C. Bronner, L. Zaayter, T. Ahmad, L. Richert et al., Interaction of the epigenetic integrator UHRF1 with the myst domain of TIP60 inside the cell. J. Exp. Clin. Cancer Res. 36(1), 188 (2017). https://doi.org/10.1186/ s13046-017-0659-1

89. W. Liu, Y. Cui, W. Ren, J. Irudayaraj, Epigenetic biomarker screening by FLIM-FRET for combination therapy in ER+ breast cancer. Clin. Epigenetics 11(1), 16 (2019). https://doi. org/10.1186/s13148-019-0620-6

90. Q. Liu, E.J. Osterlund, X. Chi, J. Pogmore, B. Leber et al., Bim escapes displacement by BH3-mimetic anti-cancer drugs by double-bolt locking both Bcl-xl and Bcl-2. Elife 8, e37689 (2019). https://doi.org/10.7554/eLife.37689

91. M. Nobis, E.J. McGhee, D. Herrmann, A. Magenau, J.P. Morton et al., Monitoring the dynamics of src activity in response to anti-invasive dasatinib treatment at a subcellular level using dual intravital imaging. Celll Adhes Migr. 8(5), 478-486 (2014). https://doi.org/10.4161/19336918.2014. 970004

92. W. Hu, Q. Wang, X. Miao, L. Bai, L. Li et al., Heteroatomcontaining organic molecule for two-photon fluorescence lifetime imaging and photodynamic therapy. J. Phys. Chem. C 122(36), 20945-20951 (2018). https://doi.org/10.1021/acs. jpcc. 8 b05460
93. S. Kalinina, J. Breymayer, K. Reess, L. Lilge, A. Mandel et al., Correlation of intracellular oxygen and cell metabolism by simultaneous PLIM of phosphorescent TLD1433 and FLIM of NAD(P)H. J. Biophotonics 11(10), 11 (2018). https://doi.org/10.1002/jbio.201800085

94. J. Kuil, P. Steunenberg, P.T.K. Chin, J. Oldenburg, K. Jalink et al., Peptide-functionalized luminescent iridium complexes for lifetime imaging of CXCR4 expression. ChemBioChem 12(12), 1896-1902 (2011). https://doi.org/10.1002/cbic. 201100271

95. Y. Ardeshirpour, D.L. Sackett, J.R. Knutson, A.H. Gandjbakhche, Using in vivo fluorescence lifetime imaging to detect HER2-positive tumors. EJNMMI Res. 8(1), 26 (2018). https://doi.org/10.1186/s13550-018-0384-6

96. T.J. Lynch, D.W. Bell, R. Sordella, S. Gurubhagavatula, R.A. Okimoto et al., Activating mutations in the epidermal growth factor receptor underlying responsiveness of non-small-cell lung cancer to gefitinib. N. Engl. J. Med. 350(21), 2129-2139 (2004). https://doi.org/10.1056/NEJMoa040938

97. D.J. Slamon, G.M. Clark, S.G. Wong, W.J. Levin, A. Ullrich et al., Human breast cancer: correlation of relapse and survival with amplification of the HER-2/neu oncogene. Science 235(4785), 177-182 (1987). https://doi.org/10.1126/science. 3798106

98. G. Weitsman, P.R. Barber, L.K. Nguyen, K. Lawler, G. Patel et al., HER2-HER3 dimer quantification by FLIM-FRET predicts breast cancer metastatic relapse independently of HER2 IHC status. Oncotarget 7(32), 51012-51026 (2016). https:// doi.org/10.18632/oncotarget.9963

99. G. Weitsman, N.J. Mitchell, R. Evans, A. Cheung, T.L. Kalber et al., Detecting intratumoral heterogeneity of EGFR activity by liposome-based in vivo transfection of a fluorescent biosensor. Oncogene 36(25), 3618-3628 (2017). https:// doi.org/10.1038/onc.2016.522

100. O. Coban, L.C. Zanetti-Dominguez, D.R. Matthews, D.J. Rolfe, G. Weitsman et al., Effect of phosphorylation on EGFR dimer stability probed by single-molecule dynamics and FRET/FLIM. Biophys. J. 108(5), 1013-1026 (2015). https:// doi.org/10.1016/j.bpj.2015.01.005

101. A.S. Cohen, R. Patek, S.A. Enkemann, J.O. Johnson, T. Chen et al., Delta-opioid receptor ( $\delta \mathrm{OR})$ targeted near-infrared fluorescent agent for imaging of lung cancer: Synthesis and evaluation in vitro and in vivo. Bioconjug. Chem. 27(2), 427-438 (2016). https://doi.org/10.1021/acs.bioconjchem. $5 \mathrm{~b} 00516$

102. S. Chattoraj, M.A. Amin, S. Mohapatra, S. Ghosh, K. Bhattacharyya, Cancer cell imaging using in situ generated gold nanoclusters. ChemPhysChem 17(1), 61-68 (2016). https:// doi.org/10.1002/cphc.201500731

103. G. Yahav, A. Hirshberg, O. Salomon, N. Amariglio, L. Trakhtenbrot et al., Fluorescence lifetime imaging of DAPIstained nuclei as a novel diagnostic tool for the detection and classification of B-cell chronic lymphocytic leukemia. Cytometry A 89(7), 644-652 (2016). https://doi.org/10.1002/ cyto.a. 22890 
104. L.Y. Liu, W. Liu, K.N. Wang, B.C. Zhu, X.Y. Xia et al., Quantitative detection of G-quadruplex DNA in live cells based on photon counts and complex structure discrimination. Angew. Chem. Int. Ed. 59(24), 9719-9726 (2020). https://doi.org/10.1002/anie.202002422

105. T.-Y. Tseng, S.-Y. Liu, C.-L. Wang, T.-C. Chang, Antisense oligonucleotides used to identify telomeric g-quadruplexes in metaphase chromosomes and fixed cells by fluorescence lifetime imaging microscopy of o-BMVC foci. Molecules 25(18), 4083 (2020). https://doi.org/10.3390/molecules2 5184083

106. N.P. Damayanti, K. Buno, S.L.V. Harbin, J.M.K. Irudayaraj, Epigenetic process monitoring in live cultures with peptide biosensors. ACS Sensors 4(3), 562-565 (2019). https://doi. org/10.1021/acssensors.8b01134

107. E. Kočišová, P. Praus, J. Bok, S. Bonneau, F. Sureau, Intracellular monitoring of As1411 aptamer by time-resolved microspectrofluorimetry and fluorescence imaging. J. Fluoresc. 25(5), 1245-1250 (2015). https://doi.org/10.1007/ s10895-015-1612-3

108. C. Ripoll, A. Orte, L. Paniza, M.J. Ruedas-Rama, A quantum dot-based FLIM glucose nanosensor. Sensors 19(22), 16 (2019). https://doi.org/10.3390/s19224992

109. T. Yoshihara, R. Maruyama, S. Shiozaki, K. Yamamoto, S. Kato et al., Visualization of lipid droplets in living cells and fatty livers of mice based on the fluorescenceof pi-extended coumarin using fluorescence lifetime imaging microscopy. Anal. Chem. 92(7), 4996-5003 (2020). https://doi.org/10. 1021/acs.analchem.9b05184

110. J.R. Lazzari-Dean, A.M. Gest, E.W. Miller, Optical estimation of absolute membrane potential using fluorescence lifetime imaging. Elife 8, 29 (2019). https://doi.org/10.7554/ eLife. 44522

111. I.A. Okkelman, D.B. Papkovsky, R.I. Dmitriev, Estimation of the mitochondrial membrane potential using fluorescence lifetime imaging microscopy. Cytom. Part A 97(5), 471-482 (2019). https://doi.org/10.1002/cyto.a.23886

112. V.G. Almendro-Vedia, C. Garcia, R. Ahijado-Guzman, D. de la Fuente-Herreruela, M. Munoz-Ubeda et al., Supramolecular zippers elicit interbilayer adhesion of membranes producing cell death. Biochim. Biophys. Acta-Gen. Subj. 1862(12), 2824-2834 (2018). https://doi.org/10.1016/j.bbagen.2018.08. 018

113. S. Gonzalez Rubio, N. Montero Pastor, C. Garcia, V.G. Almendro-Vedia, I. Ferrer et al., Enhanced cytotoxic activity of mitochondrial mechanical effectors in human lung carcinoma h520 cells: Pharmaceutical implications for cancer therapy. Front. Oncol. 8, 8 (2018). https://doi.org/10.3389/ fonc.2018.00514

114. X. Liu, W. Chi, Q. Qiao, S.V. Kokate, E.P. Cabrera et al., Molecular mechanism of viscosity sensitivity in bodipy rotors and application to motion-based fluorescent sensors. ACS Sens. 5(3), 731-739 (2020). https://doi.org/10.1021/acsse nsors.9b01951

115. M.V. Shirmanova, M.M. Lukina, L.E. Shimolina, M.K. Kuimova, V.V. Dudenkova et al., in Probing Energy Metabolism and Microviscosity in Cancer Using FLIM. ed.by BROWN J Q, VANLEEUWEN T G (Spie-Int Soc Optical Engineering; Bellingham, 2017), paper1041102, pp.1-5

116. M.V. Shirmanova, L.E. Shimolina, M.M. Lukina, E.V. Zagaynova, M.K. Kuimova, Live cell imaging of viscosity in 3d tumour cell models. Adv. Exp. Med. Biol. 1035, 143-153 (2017). https://doi.org/10.1007/978-3-319-67358-5_10

117. L.E. Shimolina, M.A. Izquierdo, I. López-Duarte, J.A. Bull, M.V. Shirmanova et al., Imaging tumor microscopic viscosity in vivo using molecular rotors. Sci. Rep. 7, 41097 (2017). https://doi.org/10.1038/srep41097

118. N. O’Donnell, I.A. Okkelman, P. Timashev, T.I. Gromovykh, D.B. Papkovsky et al., Cellulose-based scaffolds for fluorescence lifetime imaging-assisted tissue engineering. Acta Biomater. 80, 85-96 (2018). https://doi.org/10.1016/j.actbio. 2018.09.034

119. H. Wang, H. Yang, Z.P. Xu, X. Liu, M.S. Roberts et al., Anionic long-circulating quantum dots for long-term intravital vascular imaging. Pharmaceutics 10(4), 8 (2018). https://doi. org/10.3390/pharmaceutics10040244

120. N. Li, Z. Huang, X. Zhang, X. Song, Y. Xiao, Reflecting size differences of exosomes by using the combination of membrane-targeting viscosity probe and fluorescence lifetime imaging microscopy. Anal. Chem. 91(23), 15308-15316 (2019). https://doi.org/10.1021/acs.analchem.9b04587

121. F. Wong, O. Coban, G. Weitsman, T. Ng, Integrating imaging, exosome and protein network rewiring information to track early tumour evolution of resistance mechanisms. Converg. Sci. Phys. Oncol. 3(1), 9 (2017). https://doi.org/10.1088/ 2057-1739/aa5cbd

122. R.K. Koninti, S. Palvai, S. Satpathi, S. Basu, P. Hazra, Loading of an anti-cancer drug into mesoporous silica nano-channels and its subsequent release to DNA. Nanoscale 8(43), 18436-18445 (2016). https://doi.org/10.1039/c6nr06285g

123. H. Saari, E. Lisitsyna, K. Rautaniemi, T. Rojalin, L. Niemi et al., FLIM reveals alternative EV-mediated cellular up-take pathways of paclitaxel. J. Control. Release 284, 133-143 (2018). https://doi.org/10.1016/j.jconrel.2018.06.015

124. G. Caracciolo, S. Palchetti, L. Digiacomo, R.Z.Z. Chiozzi, A.L. Capriotti et al., Human biomolecular corona of liposomal doxorubicin: the overlooked factor in anticancer drug delivery. ACS Appl. Mater. Interfaces 10(27), 22951-22962 (2018). https://doi.org/10.1021/acsami.8b04962

125. A.L.B. Seynhaeve, B.M. Dicheva, S. Hoving, G.A. Koning, T.L.M. ten Hagen, Intact doxil is taken up intracellularly and released doxorubicin sequesters in the lysosome: evaluated by in vitro/in vivo live cell imaging. J. Control. Release 172(1), 330-340 (2013). https://doi.org/10.1016/j.jconrel.2013.08. 034

126. U. Alexiev, P. Volz, A. Boreham, R. Brodwolf, Time-resolved fluorescence microscopy (FLIM) as an analytical tool in skin nanomedicine. Eur. J. Pharm. Biopharm. 116, 111-124 (2017). https://doi.org/10.1016/j.ejpb.2017.01.005

127. E. Tawagi, C. Massmann, H. Chibli, J.L. Nadeau, Differential toxicity of gold-doxorubicin in cancer cells vs. Cardiomyocytes as measured by real-time growth assays and 
fluorescence lifetime imaging microscopy (FLIM). Analyst 140(16), 5732-5741 (2015). https://doi.org/10.1039/c5an0 $0446 b$

128. E. Quagliarini, R. Di Santo, D. Pozzi, P. Tentori, F. Cardarelli et al., Mechanistic insights into the release of doxorubicin from graphene oxide in cancer cells. Nanomaterials 10(8), 1482 (2020). https://doi.org/10.3390/nano10081482

129. T. Zhou, T. Luo, J. Song, J. Qu, Phasor-fluorescence lifetime imaging microscopy analysis to monitor intercellular drug release from a $\mathrm{pH}$-sensitive polymeric nanocarrier. Anal. Chem. 90(3), 2170-2177 (2018). https://doi.org/10.1021/ acs.analchem.7b04511

130. S. Suarasan, A.M. Craciun, E. Licarete, M. Focsan, K. Magyari et al., Intracellulardynamic disentangling of doxorubicin release from luminescent nanogold carriers by fluorescence lifetime imaging microscopy (FLIM) under two-photon excitation. ACS Appl. Mater. Interfaces 11(8), 7812-7822 (2019). https://doi.org/10.1021/acsami.8b21269

131. H. Ge, F. Cortezon-Tamarit, H.-C. Wang, A.C. Sedgwick, R.L. Arrowsmith et al., Multiphoton fluorescence lifetime imaging microscopy (FLIM) and super-resolution fluorescence imaging with a supramolecular biopolymer for the controlled tagging of polysaccharides. Nanoscale 11(19), 9498-9507 (2019). https://doi.org/10.1039/c8nr10344e

132. T. Nagy-Simon, A.S. Tatar, A.M. Craciun, A. Vulpoi, M.A. Jurj et al., Antibody conjugated, raman tagged hollow goldsilver nanospheres for specific targeting and multimodal dark-field/SERS/two photon-FLIM imaging of CD19(+) B lymphoblasts. ACS Appl. Mater. Interfaces 9(25), 2115521168 (2017). https://doi.org/10.1021/acsami.7b05145

133. H.S. Nam, W.J. Kang, M.W. Lee, J.W. Song, J.W. Kim et al., Multispectral analog-mean-delay fluorescence lifetime imaging combined with optical coherence tomography. Biomed.
Opt. Express 9(4), 1930-1947 (2018). https://doi.org/10. 1364/boe.9.001930

134. B. Shen, J. Yan, S. Wang, F. Zhou, Y. Zhao et al., Label-free whole-colony imaging and metabolic analysis of metastatic pancreatic cancer by an autoregulating flexible optical system. Theranostics 10(4), 1849-1860 (2020). https://doi.org/ $10.7150 /$ thno.40869

135. M.M. Karasev, O.V. Stepanenko, K.A. Rumyantsev, K.K. Turoverov, V.V. Verkhusha, Near-infrared fluorescent proteins and their applications. Biochemistry 84(Suppl 1), 32-50 (2019). https://doi.org/10.1134/s0006297919140037

136. V. Venkataramani, D.I. Tanev, C. Strahle, A. Studier-Fischer, L. Fankhauser et al., Glutamatergic synaptic input to glioma cells drives brain tumour progression. Nature 573(7775), 532-538 (2019). https://doi.org/10.1038/s41586-019-1564-x

137. T. Le Bourgeois, L. Strauss, H.-I. Aksoylar, S. Daneshmandi, P. Seth et al., Targeting T cell metabolism for improvement of cancer immunotherapy. Front. Oncology 8, 237 (2018). https://doi.org/10.3389/fonc.2018.00237

138. Z. Li, X. Zhu, S. Huang, Extracellular vesicle long non-coding RNAs and circular RNAs: biology, functions and applications in cancer. Cancer Lett. 489, 111-120 (2020). https://doi. org/10.1016/j.canlet.2020.06.006

139. A. Abramowicz, M.D. Story, The long and short of it: the emerging roles of non-coding RNA in small extracellular vesicles. Cancers 12(6), 17 (2020). https://doi.org/10.3390/ cancers 12061445

140. K. O’Brien, K. Breyne, S. Ughetto, L.C. Laurent, X.O. Breakefield, RNA delivery by extracellular vesicles in mammalian cells and its applications. Nat. Rev. Mol. Cell Biol. 21(10), 585-606 (2020). https://doi.org/10.1038/ s41580-020-0251-y 